\title{
Towards the integration of urban sound planning in urban development processes: the study of four test sites within the SONORUS project
}

DOI 10.1515/noise-2015-0005

Received Sep 11, 2015; accepted Dec 09, 2015

\begin{abstract}
Noise pollution in urban environments is today a major problem affecting inhabitants of many European cities. Reducing noise is therefore a necessity. As a result, many cities now have noise action plans comprising concrete actions to tackle noise issues in affected areas. Nevertheless, these often isolated documents only address existing problems. In order to change this practice an integrated strategy is necessary. A new approach to urban sound planning, a holistic approach, is being developed and tested within the SONORUS project and it is described in this paper. SONORUS, the Urban Sound Planner project, is an initial training network (ITN) that is educating researchers in a whole range of acoustic disciplines, as well as in advanced urban planning processes. An essential part of this training is the application of the holistic approach to real test sites. Although this is an ongoing work, a few innovative techniques were already developed and its application to the test sites resulted in improved urban sound planning tools. This paper promotes the discussion about the implications that the holistic approach might have in urban sound planning policies and how it can be a driving force for changing the noise pollution situation in urban environments.
\end{abstract}

Keywords: Urban sound planning; soundscaping; noise control and design; noise prediction methods; holistic urban planning

\footnotetext{
^Corresponding Author: Sonia Alves: Müller BBM, GmbH Planegg - Munich, Germany; Email: sonia.alves@mbbm.com Laura Estévez-Mauriz: Division of Applied Acoustics, Department of Civil and Environmental Engineering, Chalmers University of Technology, Göteborg, Sweden

Francesco Aletta: School of Architecture, University of Sheffield, UK

Gemma M. Echevarria-Sanchez: Department of Information Technology, Acoustics group, Ghent University, Belgium
}

\section{Introduction}

One of the biggest consequences of urbanisation is environmental noise, being road traffic the most dominant source. Recent studies [1, 2] indicate that urban noise, in particular from road traffic, is the second major environmental risk for Europeans, estimating that 125 million people are affected by noise levels considered harmful. Well known effects of noise-exposure include sleep disturbance, cardiovascular diseases, annoyance and cognitive impairment, particularly on children [1]. Such evidence has increased the concern about environmental noise in Europe, which is reflected in the Environmental Noise Directive (END) [3]. The END imposes to its members to report noise maps and more importantly, the definition and implementation of action plans for larger urban areas, major roads, railways and airports, with the aim to reduce population exposure to noise. However, the second round of noise mapping and action plans from agglomerations had a low participation [1]. Nevertheless, it is estimated that by 2020, the number of people living in cities will dramatically increase, and $80 \%$ of Europeans will be living in urban areas [4]. This tremendous densification is catalogued as a major global health issue in the $21^{\text {st }}$ century [5], with the consequent pressure from environmental noise pollution.

In order to respond to the increasing population and rural-urban migration processes, an unprecedented transformation of the landscape and the environment is taking place, where large-scale urban planning projects are developing faster than ever [5, 6]. Unfortunately, aspects related to the urban sound planning have not been taken in consideration in most cases. Although some localized solutions are being considered, there is a need for an integrated way to urban sound planning. Such challenge

Virginia Puyana Romero: Department of Architecture and Industrial Design, Seconda Università di Napoli, Aversa, Italy 
requires a holistic approach, connecting all stakeholders and different aspects of liveability into a single coherent solution. This task goes beyond the skills and scope of existing urban planners, leading to a new type of specialist that encompasses the concept of acoustic environment, as the "Urban Sound Planner".

The holistic approach to urban sound planning, within SONORUS project, means that urban sound planners should be involved in the planning process from the beginning; the acoustic interventions should be extended from pure noise control to sound quality and sound design; acoustic aspects altogether should be considered as one independent planning discipline [7]. Only if urban sound planners are involved earlier in the planning process it is possible to contribute with sound design solutions, concentrate on preventing the occurrence of noise, not limiting the interventions to the obvious noise engineering solutions, and coordinating actions of different acoustic research topics to provide an integrated solution.

The working concept for the application of the holistic approach involves a strong interaction with all the stakeholders and the consideration for social, economic, cultural, historical, and technical factors. The definition of acoustic objectives is very important: besides noise limits, the consideration for the human perception of sound is essential [8]. As a consequence, the implementation of the holistic approach demands more than the traditional noise engineering tools. Therefore the application of new tools will have a relevant role for a successful implementation. In the last years, this was the research topic of several EU projects [9]. Innovative research provided new solutions for urban sound planning such as: the use of green noise barriers, different types of soil, or recycled materials to abate noise and improve the perception of the sound environment, particularly on urban environments. This was the research topic of the HOSANNA project [10]. A new index reflecting public's perception of noise was developed within the HARMONICA project. It facilitates the communication of acoustic considerations to all stakeholders, including non-experts [11]. The integration of the quiet side concept in urban planning and its positive effects were studied in QSide [12] and QUADMAP [13] projects. These are just a few examples of research outcomes for urban sound planning from recent EU projects. However, the integration and connection of knowledge with planning authorities has not yet been extensively covered. SONORUS aims to fill this gap through the training and education of researchers in diverse areas of acoustical knowledge, urban planning and communication. These professionals will thus be prepared to work with the urban planning authorities, aiming to contribute to reverse the ac- tual situation of poor urban acoustic environment [14, 15]. In this sense, SONORUS' city partners (Antwerp, Brighton \& Hove, Gothenburg and Rome) are very important for the project's concept, as they provide test sites where the holistic approach is being implemented and the feasibility of this methodology can be tested with actual planning problems.

The purpose of this paper is:

- to determine and analyse the inclusion of a holistic urban sound planning into the general urban planning process;

- to test how the holistic approach can be applied attending to the different needs of the four test sites;

- to present the outcomes of the holistic approach and a critical analysis (SWOT) on its practical implementation.

The improvement and/or preservation of the acoustic environment of public spaces is one major concern of the four test sites. Three methodologies are pursued according to the research themes in the SONORUS project, the working group background and the test site needs: soundscaping (Rome and Brighton \& Hove), noise control and design (Antwerp) and noise prediction methods (Gothenburg). Consultation of stakeholders' perception about the sound environment or the integration of different technical disciplines to design a final solution are examples of the common strategy, implemented in all test sites, based on the holistic approach.

In order to meet challenges proposed by city-partners as part of the bigger urban planning context, this paper starts by analyzing each test site including: a general contextualization of the city; a description of specific challenges presented by each test site; and the research carried out. To reflect on the practical implementation of the holistic urban sound planning approach, the discussion section includes an overview of each test site holistic implementation. This overview is driven by a SWOT analysis to assess the implications that this approach might have for urban sound planning in the future.

\section{Test sites analysis}

In order to analyse the inclusion of the holistic approach of urban sound planning, as well as the developed research and results obtained to improve and/or preserve the acoustic environment, the four test sites included are presented in the next paragraphs, namely: Rivierenhof Park in Antwerp (Belgium), Valley Gardens in Brighton \& 


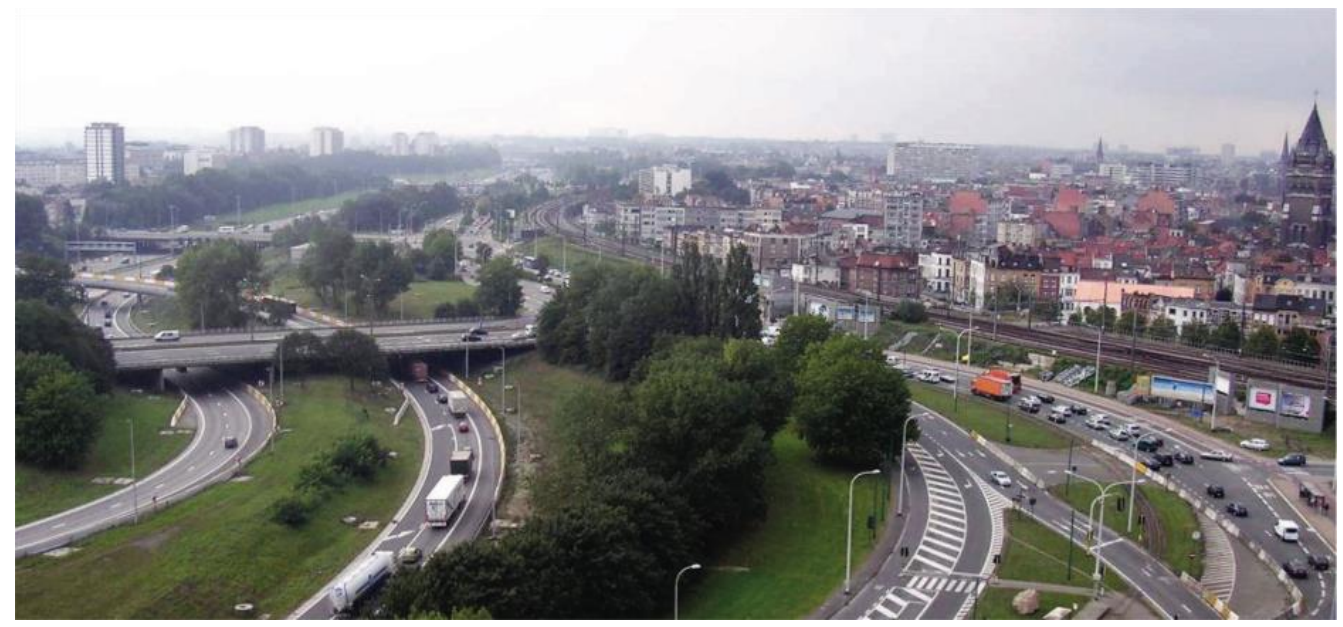

Figure 1: Aerial view of traffic road node in Antwerp provided by the City of Antwerp.

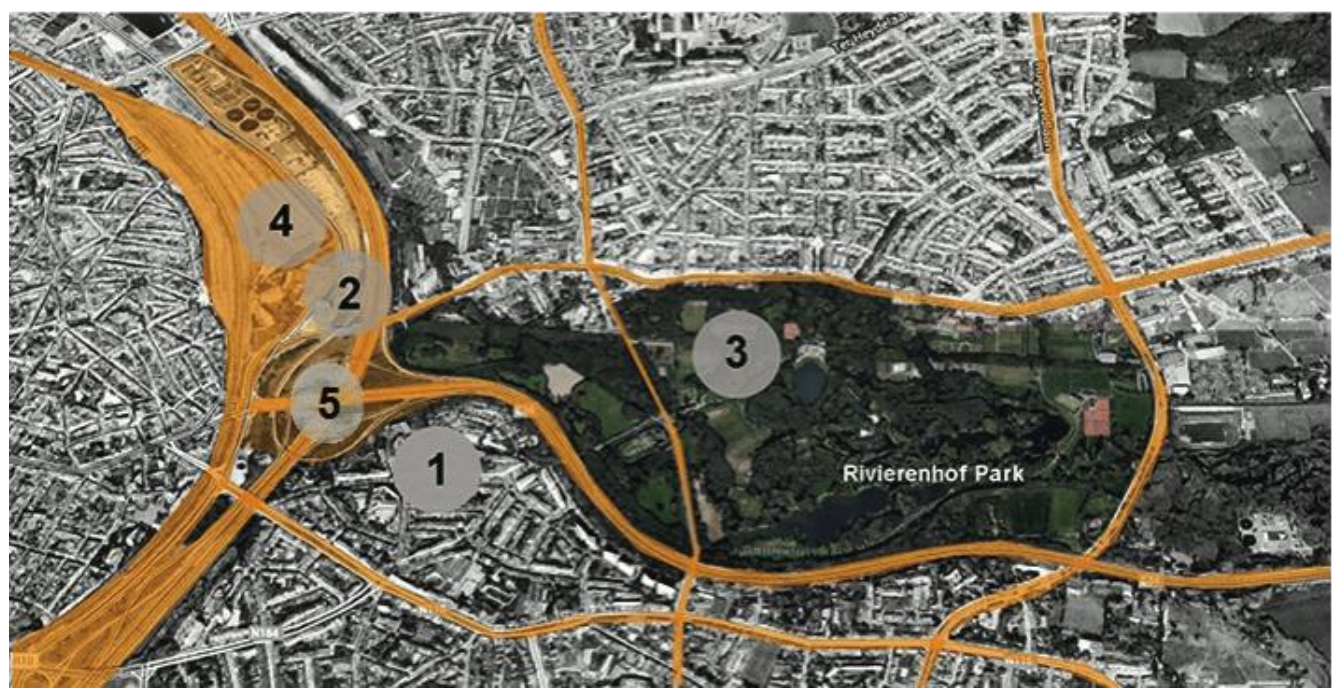

Figure 2: General map of the site and numbered areas: 1 - Tuinwijk, 2 - Hof ter Lo, 3 - Rivierenhof Park, 4 - Spoor Oost, 5 - connection with Rivierenhof Park.

Hove (United Kingdom), Frihamnen area in Gothenburg (Sweden) and Colosseum, Palatine and Roman Forum area in Rome (Italy).

\subsection{Antwerp: Rivierenhof Park}

\subsubsection{General description}

Antwerp is one of the most populated cities in Belgium [16]. The test site proposed by the city is composed of different areas affected by a road infrastructure node located at the northwest with intense traffic that combines two major road infrastructures and a ring road with local roads (Fig. 1).
The different urban configurations of these areas demand applying solutions from various approaches. Therefore this site provides an interesting exhibition of potential acoustic problems that may arise in a city. Their complexity and variety clearly shows the necessity of a holistic approach, since acoustical, architectonic and urban views were simultaneously needed to reach an efficient solution. The Antwerp test site approach focused on providing analysis, tips and viewpoints, as required by the city council representative.

For the purpose of this paper, the work related to the Rivierenhof Park will be described in detail (Area 3, see Fig. 2). 


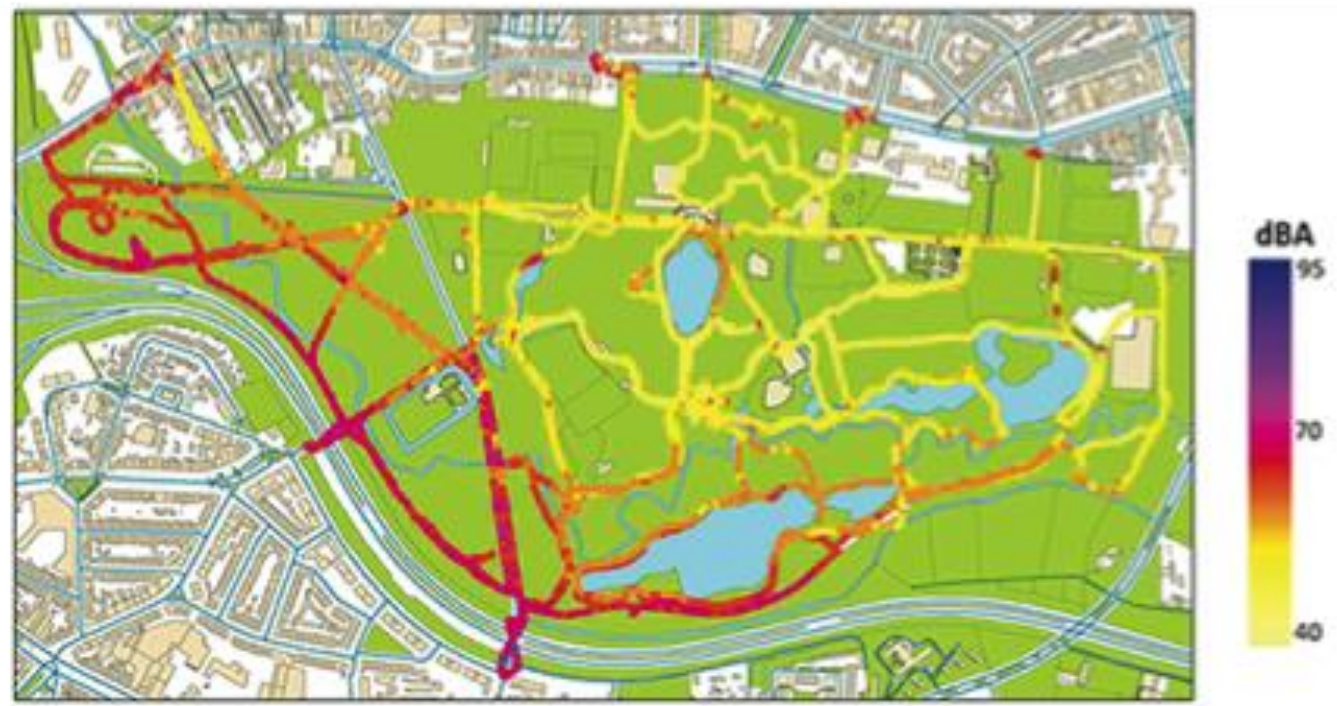

Figure 3: Noise map Rivierenhof Park (LAeq) (extracted from [17]).
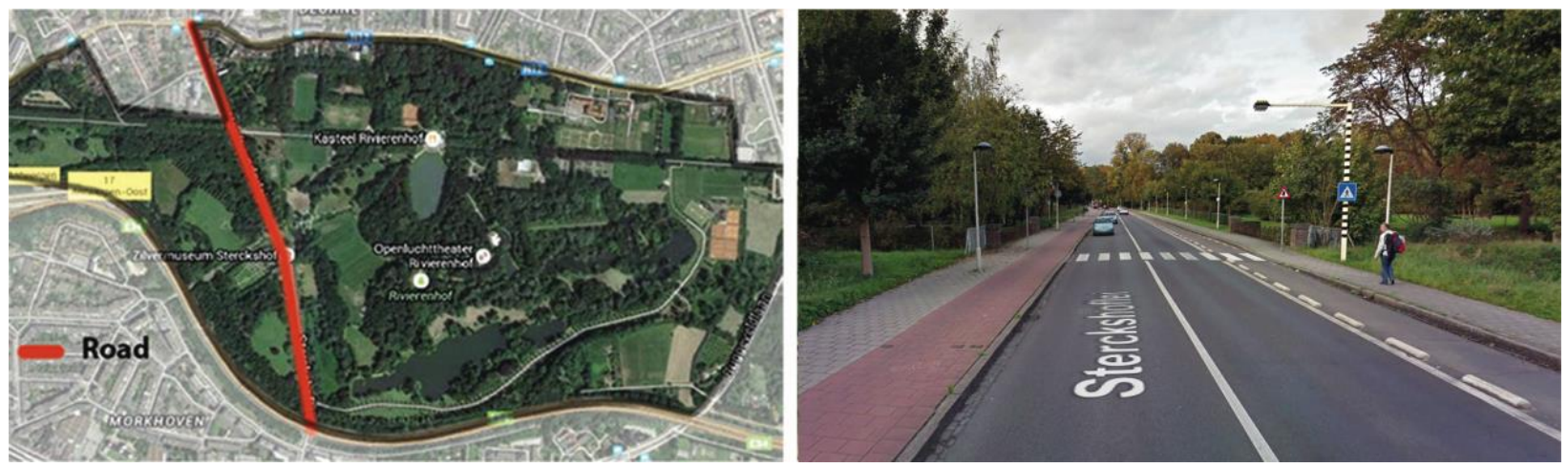

Figure 4: Road crossing Rivierenhof Park (Sterckshoflei St.)

\subsubsection{Specific challenges}

Rivierenhof Park is affected by high noise levels due to the busy E313 highway, which surrounds the park on the south side. In order to evaluate the soundscape quality of Rivierenhof Park, a study was conducted including a recording measurement campaign: audio, instantaneous 1/3-octave band levels and GPS data [17]. To allow the identification of the subjective visitor's opinion about sound environment, a questionnaire survey was completed in the same time-frame [18]. A noise map was produced as part of this research outcome (see Fig. 3). High noise levels were measured at the south and west of the park near the highway and on the road crossing the park.

The road forms part of Sterckshoflei and Hooftvunderlei street. It has a total length of $1 \mathrm{~km}$ and two traffic lanes adjacent to a bicycle and pedestrian path both sides (Fig. 4). This layout decreases pedestrian safety and in- terrupts the cohesion of the park as along the $1 \mathrm{~km}$, only 4 crossing points are settled. At the same time, the linear geometry of the road enhances vehicle acceleration and consequently, traffic noise in the middle of a green area. From the aesthetic and visual point of view, it gives the misleading impression to the visitor that this is the border of the park and the beginning of the urban built environment. Additionally, this road is a significant source of road traffic noise, with LAeq values around $70 \mathrm{~dB}$ as shown in Fig. 3 depreciating the user's experience of the park.

\subsubsection{Integration of urban sound planning}

The problems caused by the crossing road could have been prevented in a planning stage, applying a more appropriate traffic flows distribution. Currently, the road cannot be completely removed due to urban and traffic configura- 


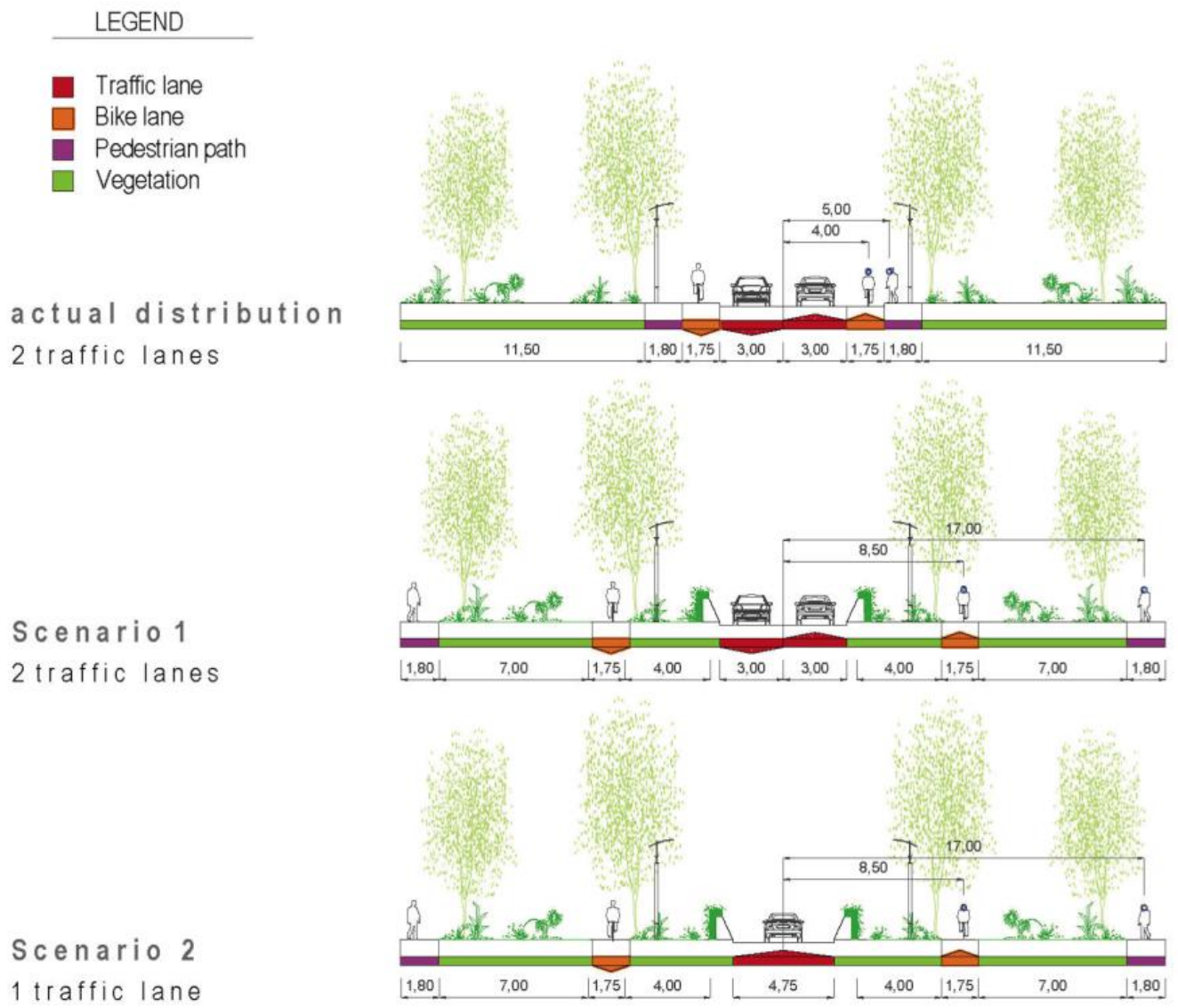

Figure 5: Scenarios modelled: current, scenario 1, scenario 2.

tion. However, following a holistic approach can mild existing problems. The working group proposed the following solutions to mitigate the problems generated by road traffic, to increase pedestrian safety, reduce traffic noise emission and increase urban green space quality:

- Separating the two traffic lanes;

- Reducing the number of lanes: redistribute the traffic flow to other possible routes bordering the park;

- Reducing traffic speed with calming measures, as the inclusion of chicanes along the road which is proved to reduce traffic speed [19]. It avoids the linear perception of the road giving visual continuity to the park;

- Adding a porous road surface material;

- Locating vegetated low barriers next to the source;

- Including absorbent vegetated areas between source and receiver to give visual continuity to the park avoiding the impression of park border;

- Locating pedestrian path and bike lane at a further distance from the road.
Most of the proposed solutions were acoustically calculated using the full wave numerical method Finite Difference Time Domain (FDTD). The addition of different shapes of low barriers was also assessed. In the FDTD method [20], sound propagation equations are solved in time-domain. The main objective is to assess the effect of the different solutions and to achieve the largest noise reduction for cyclists and pedestrians. Different noise abatement measures were tested taking into account previous work [21].

The simulation grid with $2 \mathrm{~cm}$ cell size allows a frequency accuracy up to $1 \mathrm{kHz}$ octave band. A perfectly reflective material was assigned to the road surface, the bike lane and the pedestrian path. Absorptive areas simulating vegetation substrate are modelled by a rigid-porous frame.

Imission levels are calculated in octave bands using the CNOSSOS Equivalent source model [22]. Other sources are not considered and traffic intensity is of no interest as the concerned values are relative to the current situation. A horizontal line of receivers separated $6 \mathrm{~cm}$ is positioned at $1.5 \mathrm{~m}$ height along the cross section. Values for pedestrians and cyclists are compared in different scenar- 


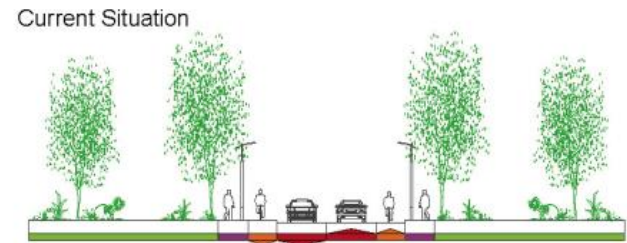

Scenario 1 (2 lanes)
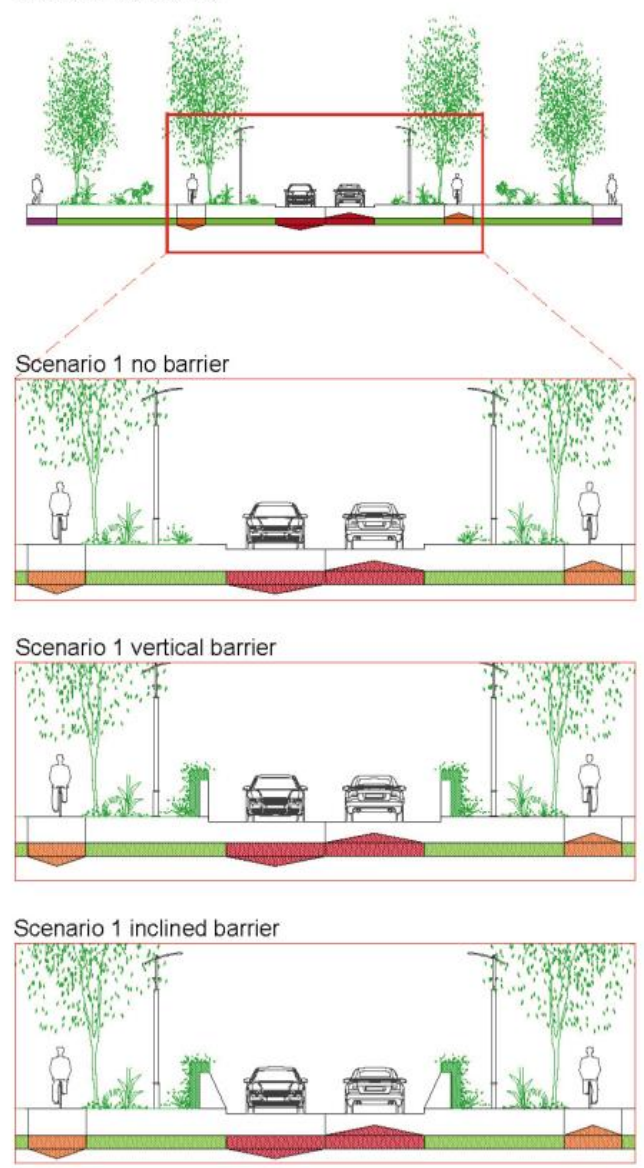

Figure 6: Cases and scenarios assessed in FDTD method

ios to reach the most suitable solution for both. The total pressure level A-weighted relative to free field is obtained for each receiver along the section at a pedestrian height. Further information about method and calculation can be found in [21].

The different noise abatement measures are included in two new scenarios (Fig. 5): scenario 1 (Sc1) keeping the two lane road, and scenario 2 (Sc2) modelling one lane road, and compared to the current situation, where both the cyclist and pedestrian path are located next to the road.

Seven different cases are calculated in total (Fig. 6). In both proposed scenarios, pedestrian and cycling path are located at a further distance from the road (8.5 and $17 \mathrm{~m}$
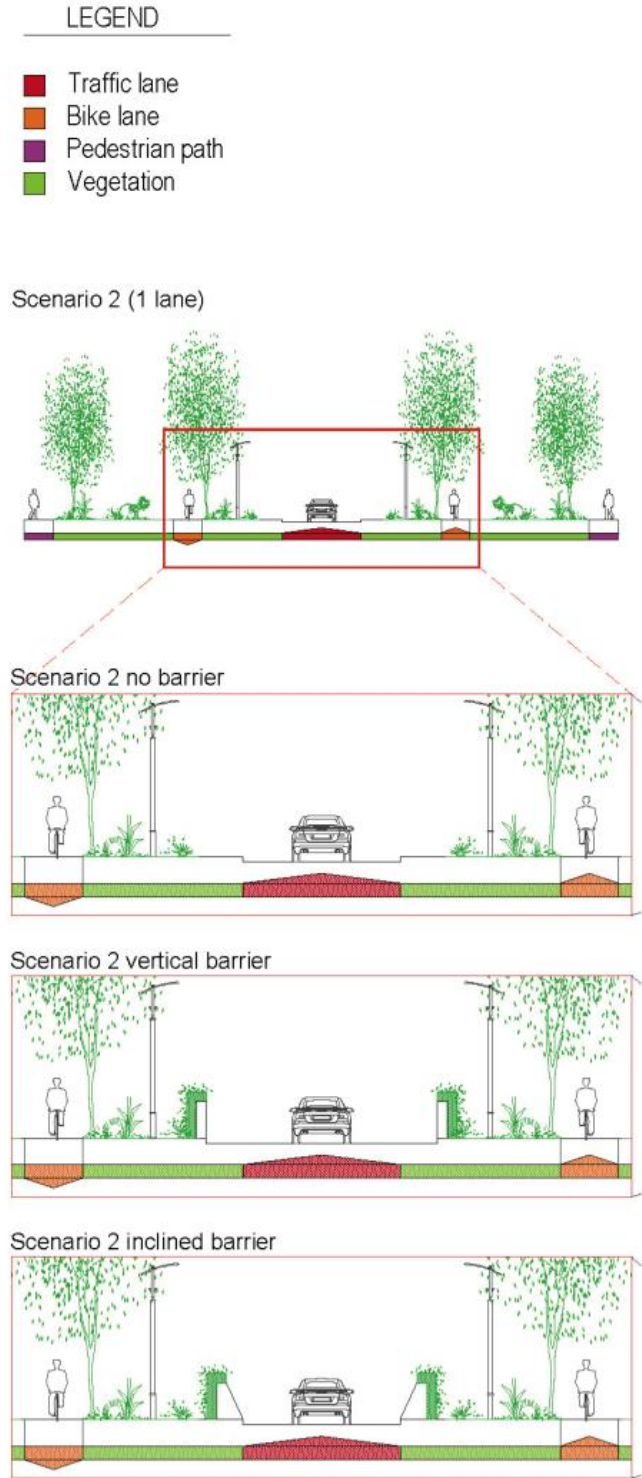

respectively), making possible to include two absorbent green areas.

Two different low barriers (vertical or 30 degrees inclined) of $1.1 \mathrm{~m}$ height have been assessed taking into account different traffic speeds (50, 40 and $30 \mathrm{~km} / \mathrm{h}$ ). Both low barriers are calculated with green absorption on the top and receiver side of the barrier [21]. The total pressure levels distribution along the section at $1.5 \mathrm{~m}$ height in the different cases are compared to the current situation and show together with the correspondent geometry for Sc1 and Sc2 (Fig. 7). The inclined low barrier for the Sc2 is the most effective solution, with a reduction of $11.5 \mathrm{~dB}(\mathrm{~A})$ in the exposure for the same position. The comparison between 


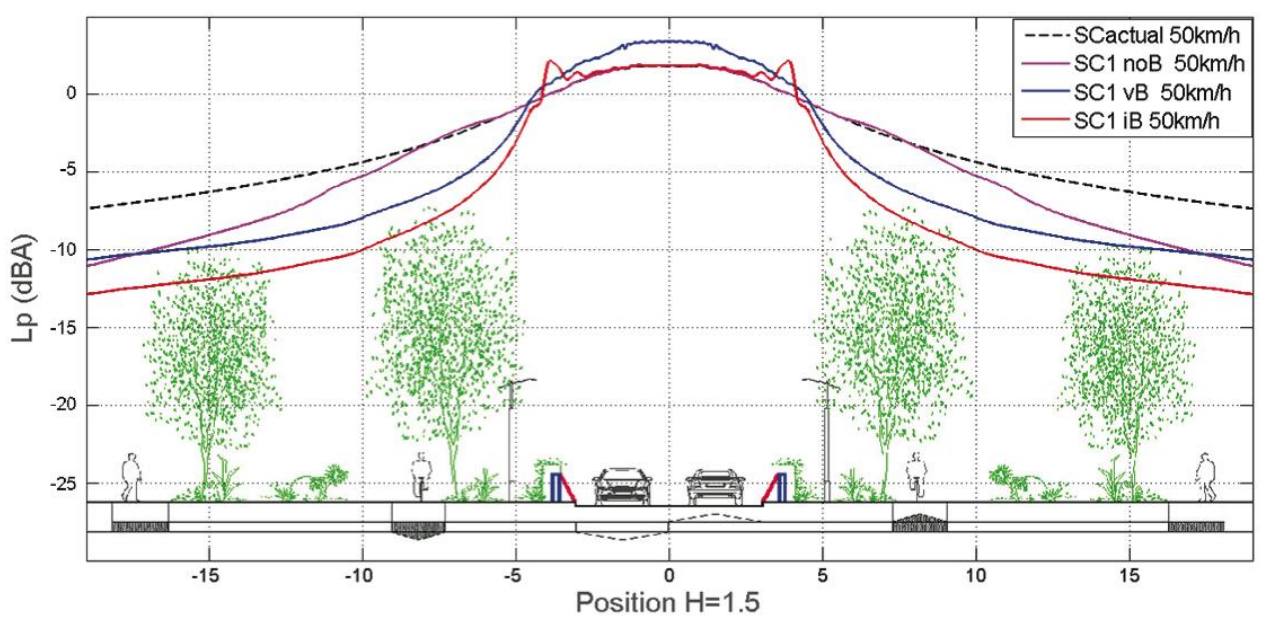

(a)

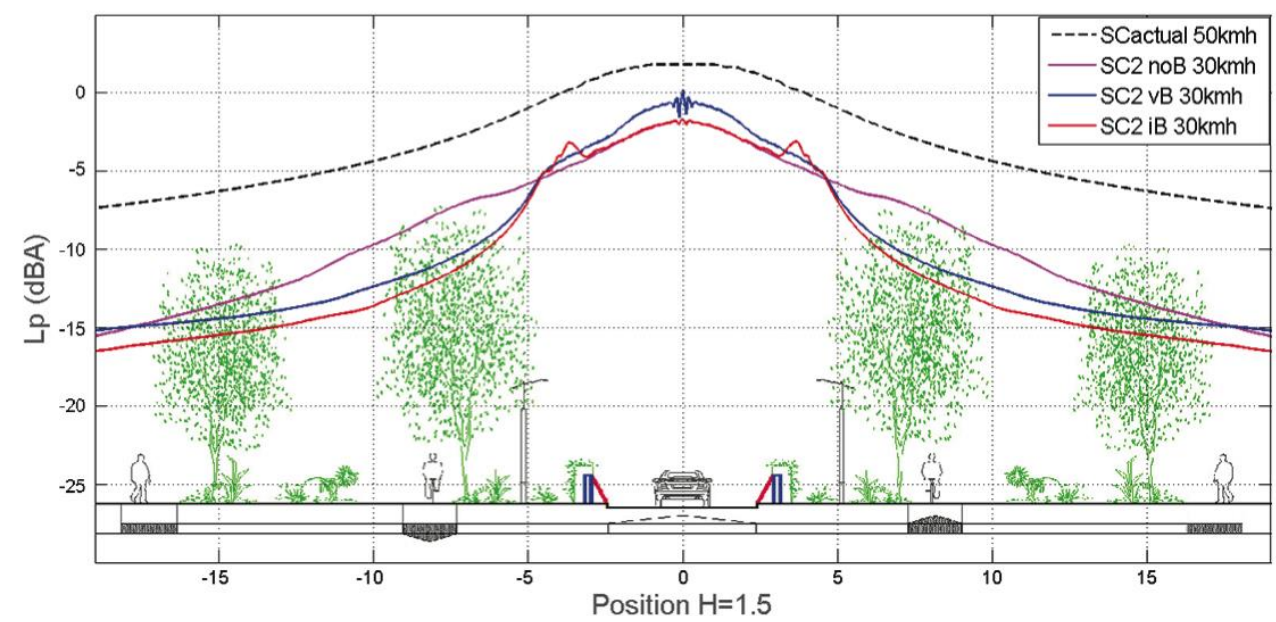

(b)

Figure 7: Noise exposure along the cross section at $1.5 \mathrm{~m}$ height: a) Scenario 1; b) Scenario 2.

the two charts show the importance of limiting the traffic speed achieving around $5 \mathrm{~dB}(\mathrm{~A})$ reduction.

The range of values along the bike lane and the pedestrian path is small (Fig. 8), where the boxplots show the noise reduction along the bike lane and the pedestrian path for the $50 \mathrm{~km} / \mathrm{h}$ cases in the $\mathrm{Sc} 1$ and for the $30 \mathrm{~km} / \mathrm{h}$ cases in the Sc2. These values are relative to the median value of cyclist lane in the actual case.

The exposure reduction in $\mathrm{dB}(\mathrm{A})$ relative to the referent values in the current case (cyclist at $4 \mathrm{~m}$ and the pedestrian at $5 \mathrm{~m}$ ) are shown in Fig. 9 and Table 1. They show large noise reductions, especially in the cases with the inclined low barrier, where a $25 \mathrm{~dB}(\mathrm{~A})$ reduction is achieved on the cyclist exposure at $8.5 \mathrm{~m}$ distance and $30 \mathrm{~dB}(\mathrm{~A})$ reduction for the pedestrian exposure at $17 \mathrm{~m}$ in the Sc2 (Figure 9).
Some main ideas can be concluded:

- The combination of different noise abatement measures proposed can reduce up to $24.7 \mathrm{~dB}(\mathrm{~A})$ for $\mathrm{cy}$ clist and up to $30 \mathrm{~dB}(\mathrm{~A})$ for pedestrians;

- The suppression of one traffic lane gives an overall reduction of around $3 \mathrm{~dB}(\mathrm{~A})$;

- Decreasing the speed from 50 to $40 \mathrm{~km} / \mathrm{h}$ reduces an overall noise level around $2.7 \mathrm{~dB}(\mathrm{~A})$. Reducing the speed from $40 \mathrm{~km} / \mathrm{h}$ to $30 \mathrm{~km} / \mathrm{h}$ additionally reduces around $3.1 \mathrm{~dB}(\mathrm{~A})$;

- The fact of displacing the cyclist and pedestrian lanes further away from the source achieves a reduction of around $7 \mathrm{~dB}(\mathrm{~A})$ and $17 \mathrm{~dB}(\mathrm{~A})$ respectively;

- Vegetated surfaces only reduce noise at far distances when large green surfaces absorb part of the sound. Reduction of around 6.5 dB(A) is achieved for pedestrians at $17 \mathrm{~m}$ from the road; 
Table 1: Noise reduction for cyclist at $8.5 \mathrm{~m}$ and pedestrian at $17 \mathrm{~m}$ from the road center in both scenarios. Vegetated substrate is considered.

\begin{tabular}{|c|c|c|c|c|c|c|c|c|c|c|}
\hline & \multicolumn{3}{|c|}{ No barrier } & \multicolumn{3}{|c|}{ Vertical barrier } & \multicolumn{3}{|c|}{ Incl low barrier } \\
\hline & & $\begin{array}{c}50 \\
\mathrm{~km} / \mathrm{h}\end{array}$ & $\begin{array}{c}40 \\
\mathrm{~km} / \mathrm{h}\end{array}$ & $\begin{array}{c}30 \\
\mathrm{~km} / \mathrm{h}\end{array}$ & $\begin{array}{c}50 \\
\mathrm{~km} / \mathrm{h}\end{array}$ & $\begin{array}{c}40 \\
\mathrm{~km} / \mathrm{h}\end{array}$ & $\begin{array}{c}30 \\
\mathrm{~km} / \mathrm{h}\end{array}$ & $\begin{array}{c}50 \\
\mathrm{~km} / \mathrm{h}\end{array}$ & $\begin{array}{c}40 \\
\mathrm{~km} / \mathrm{h}\end{array}$ & $\begin{array}{c}30 \\
\mathrm{~km} / \mathrm{h}\end{array}$ \\
\hline \multirow[t]{2}{*}{ Sc1 } & Сyc 8.5 m & -7.5 & -10.3 & -13.6 & -13.7 & -16.3 & -19.5 & -17.5 & -20.1 & -23.0 \\
\hline & Ped 17 m & -18.2 & -21.0 & -24.3 & -18.4 & -21.1 & -24.3 & -22.7 & -25.4 & -28.5 \\
\hline \multirow[t]{2}{*}{ Sc2 } & Сус 8.5 m & -10.4 & -13.2 & -16.5 & -16.8 & -19.6 & -22.8 & -19.1 & -21.7 & -24.7 \\
\hline & Ped $17 \mathrm{~m}$ & -21.2 & -23.9 & -27.2 & -21.6 & -24.3 & -27.7 & -24.2 & -26.8 & -30.0 \\
\hline
\end{tabular}

Reference values: values for cyclists at $4 \mathrm{~m}$ and pedestrians at $5 \mathrm{~m}$ (current positions)
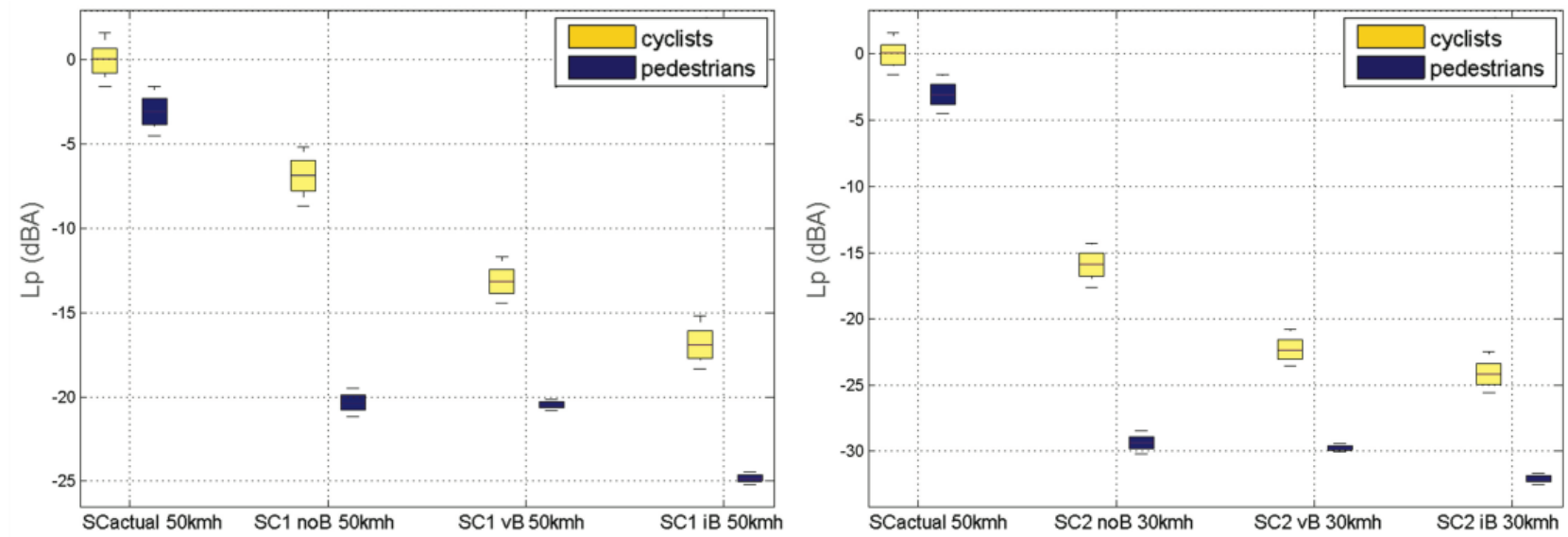

Figure 8: Noise exposure along cyclist and pedestrian path in different cases compared to the current scenario. Reference value for both is the median value for cyclists in the current case. left) Sc1. Cases at $50 \mathrm{~km} / \mathrm{h}$. right) Sc2. Cases at $30 \mathrm{~km} / \mathrm{h}$.

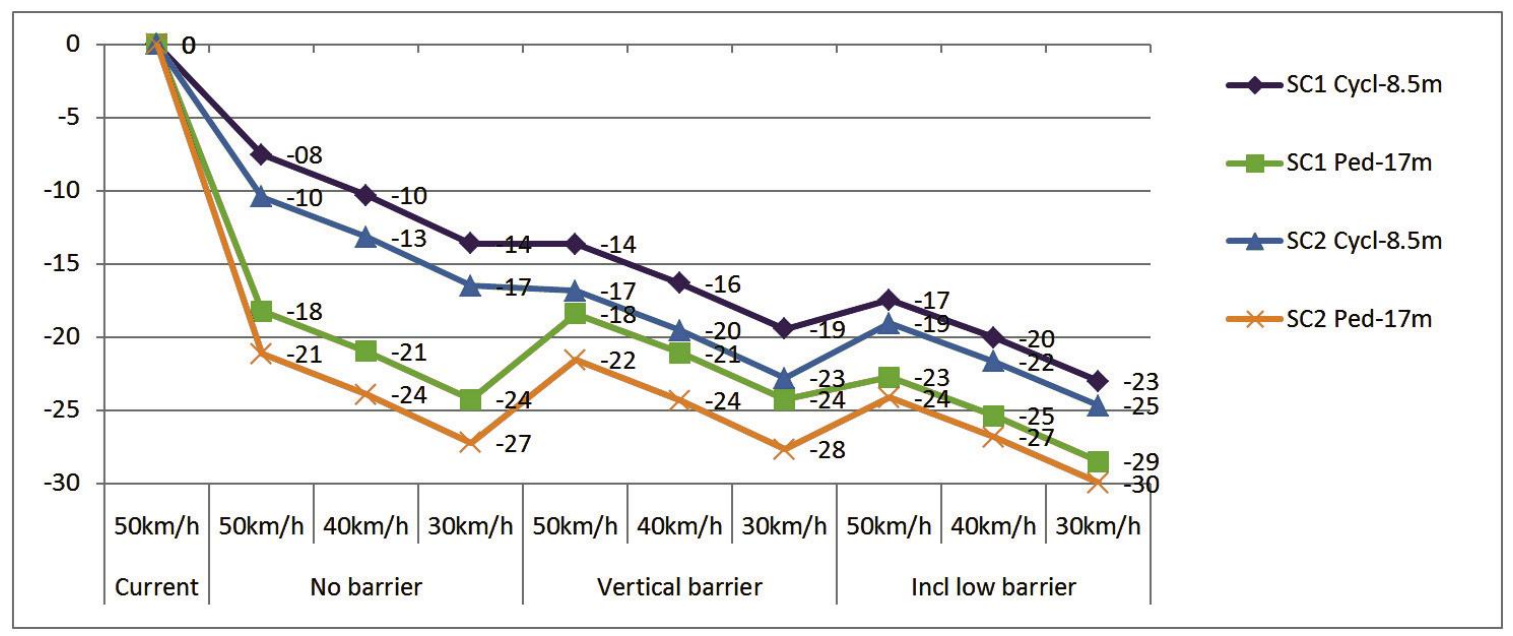

Figure 9: Noise reduction in $\mathrm{dB}(\mathrm{A})$ for cyclist at $8.5 \mathrm{~m}$ and pedestrian at $17 \mathrm{~m}$ from the road centre in both scenarios. Vegetated substrate is considered.

- The addition of a low vertical barrier reduces around $6 \mathrm{~dB}$ (A) for cyclists but practically no effect is found for pedestrians;

- The inclined barrier achieves bigger reductions than the vertical one in all cases. It additionally reduces around $4 \mathrm{~dB}(\mathrm{~A})$ in $\mathrm{Sc} 1$ and around $2 \mathrm{~dB}(\mathrm{~A})$ in $\mathrm{Sc} 2$ for cyclists. For pedestrians, a reduction of nearly $5 \mathrm{~dB}(\mathrm{~A})$ is achieved in $\mathrm{Sc} 1$ and $3 \mathrm{~dB}(\mathrm{~A})$ in Sc2. 


\subsection{Brighton \& Hove: Valley Gardens}

\subsubsection{General description}

Brighton \& Hove is a city of 250,000 residents. It was the first authentic seaside resort in the country and although it had a deceleration moment in the last decades of the twentieth century, tourism is now growing again and is certainly one of the main factors for the city development. Brighton \& Hove has a wide range of restaurants and offers a varied nightlife, which, along with the impressive arts and cultural events have created a thriving city.

The setback of being such a thriving city is pressure from tourism and night-time economy against the demands of residents' activities, directly related to the problems due to excessive noise and the nuisance it generates. The city center is affected by noise from human activities and in particular from road traffic. The Valley Gardens site is located in the city center and goes from the seafront roundabout (Brighton's pier) to approximately $1.5 \mathrm{~km}$ into the City (see Fig. 10).

This is a relevant access for entering and leaving the City and also for accessing the seaside. Consequently, it is largely affected by high noise levels from road traffic. The residents do not use the green areas along the site for their leisure activities.

Added to the problem of noise, there are also mobility issues: some road sections have a total of four lanes, not very wide sidewalks and almost non-existing cycling lanes which make it difficult for people to move around (see Fig. 11).

In this sense, a project started with the purpose to improve the area, called The Valley Gardens project involving the transformation and complete redesign of the site. The plan's aim is to upgrade the public spaces and improve routes for pedestrians, cyclists, drivers and public transport. These elements are discussed in the City's master plan, which defines the vision for the area [23]. According to the city partner description, the objective of the plan concerning noise/sound is: "Using sound as a valuable resource rather than a "waste product of poorly designed areas" - this project seeks to minimise intrusive/unwanted noise whilst at the same time introduce positive sounds".

\subsubsection{Specific challenges}

The overall goal of the City for this area, as reported in the vision for the Valley Gardens [23] is to: "become a key area of Brighton \& Hove that adds to the city's appeal. We would like Valley Gardens to be: an attractive, flexible, safe space

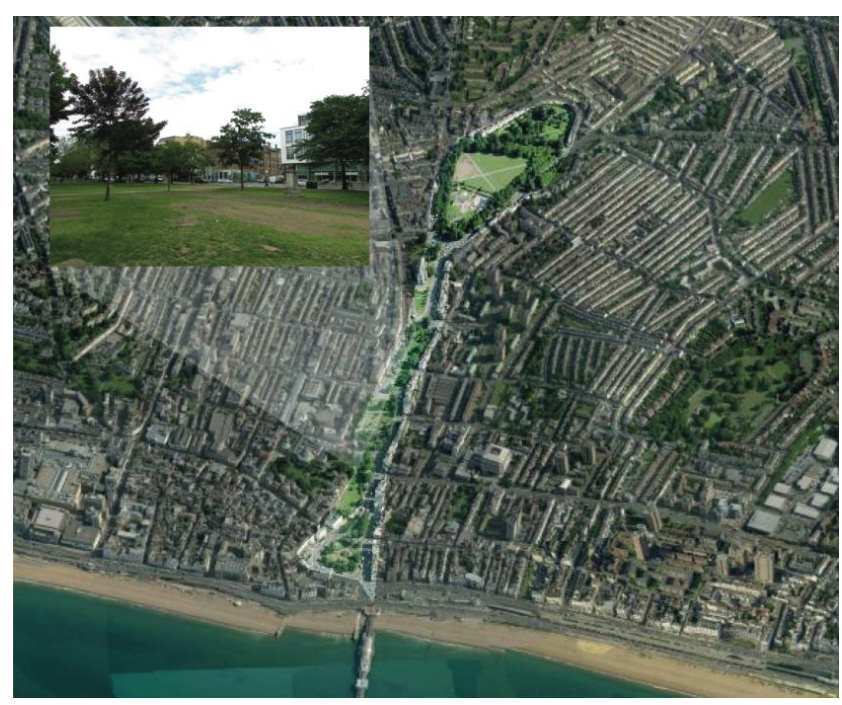

Figure 10: A view of the Valley Gardens test site.

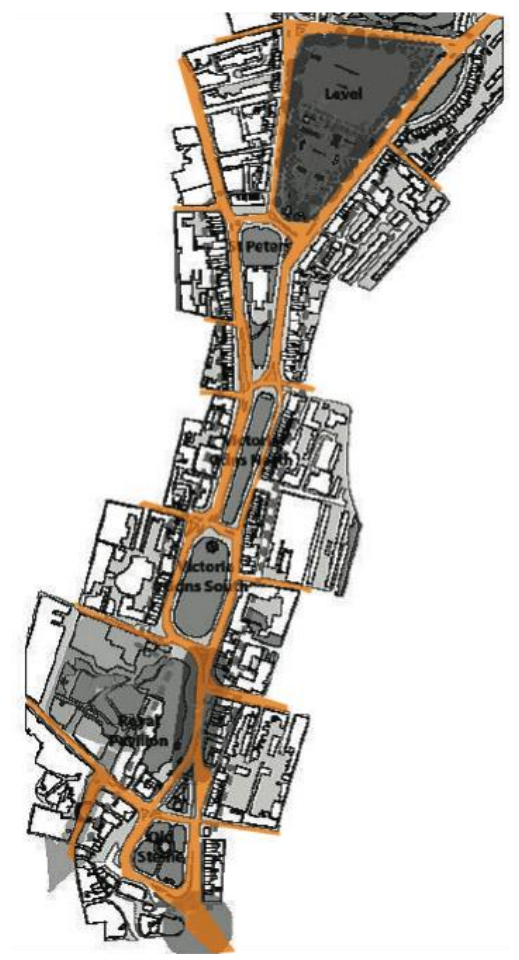

Figure 11: Valley Gardens site (courtesy of Brighton \& Hove City Council).

that enhances the city centre's environment; a place that will attract residents and visitors at all times of the day and year, with something for everyone to enjoy; a meeting place, connecting the city efficiently and safely however people travel".

Nevertheless, the current situation is deeply affected by noise problems, the entire Valley Gardens area being ex- 

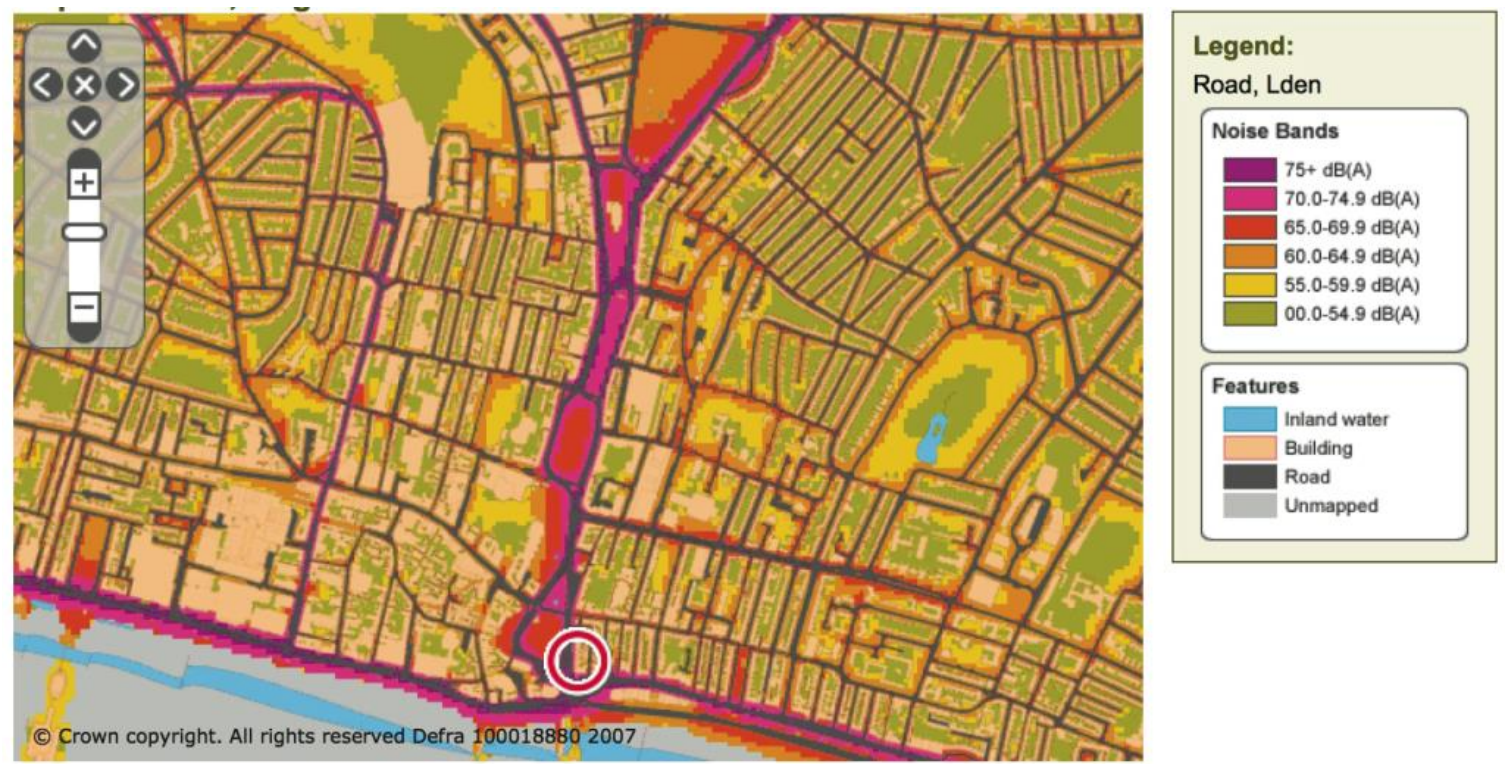

Figure 12: $L_{d e n}$ levels at Brighton city centre. The Valley Gardens area is visible immediately above the red circle [24].
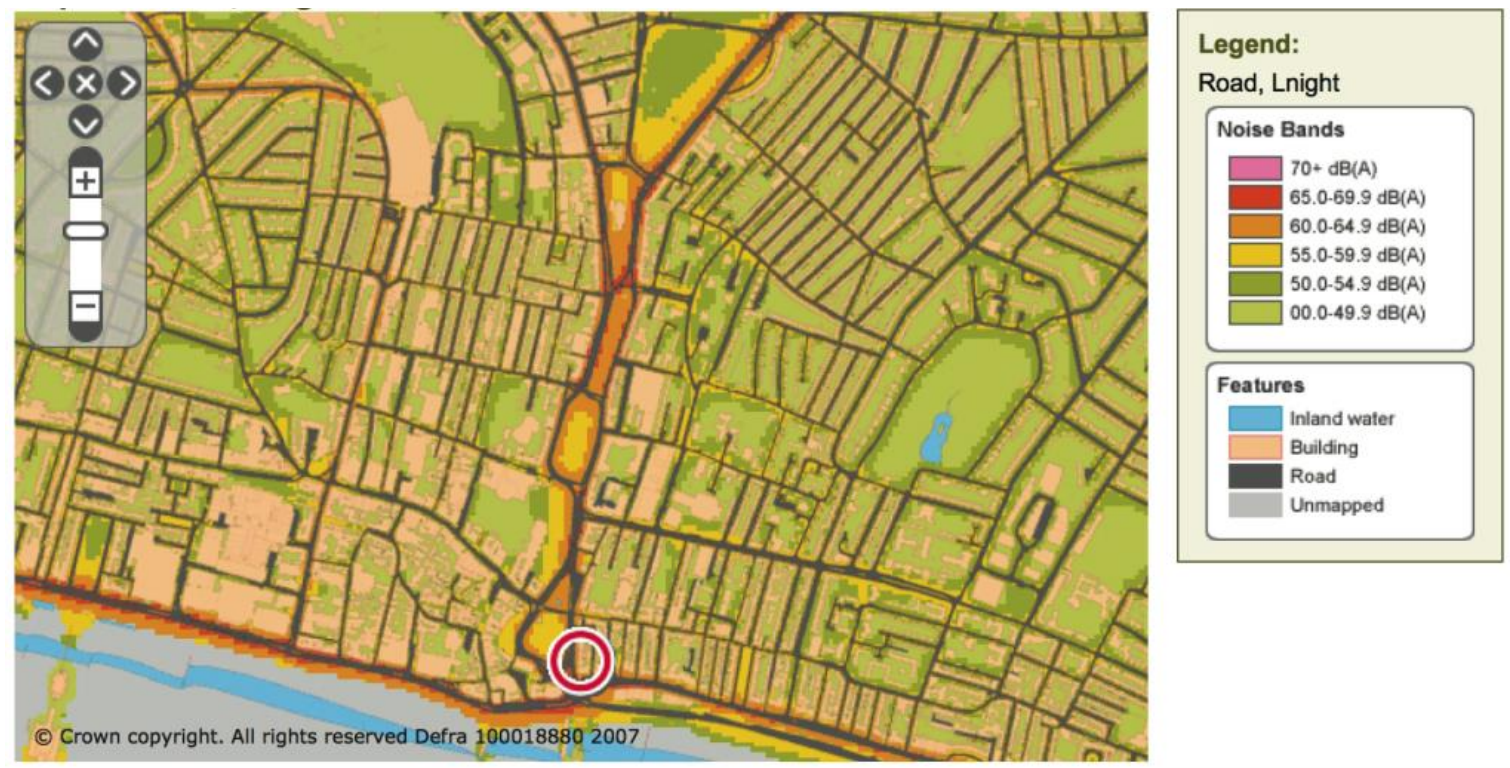

Figure 13: $L_{\text {night }}$ levels at Brighton city centre. The Valley Gardens area is visible immediately above the red circle [24].

posed to high noise levels, in particular road traffic noise. The noise map from 2013 of Brighton \& Hove is publically available [24] and noise levels on the site, are (road noise): $\mathrm{L}_{\text {den }} \geq 65 \mathrm{~dB}(\mathrm{~A})$ and $\mathrm{L}_{n} \geq 60 \mathrm{~dB}(\mathrm{~A})$ as reported in Fig. 12 and 13. Both $\mathrm{L}_{\text {den }}$ and $\mathrm{L}_{\text {night }}$ are above the recommended levels by the WHO World Health Organisation (WHO) [25] and [26] of $50 \mathrm{~dB}(\mathrm{~A})$ and $40 \mathrm{~dB}(\mathrm{~A})$, respectively. One of the first challenges proposed by the city was to tackle this problem, while improving the soundscape of the park.

\subsubsection{Integration of urban sound planning}

The ESRs working group first approach was the analysis of the current road traffic noise levels situation, but also the current sound environment in Valley Gardens. Thus, two main strategies were defined: Producing a more detailed road traffic noise map of Valley Gardens area; Characterising the sound environment in Valley Gardens both from the acoustic metrics' and the individual perception (i.e. soundscape) point of view. 


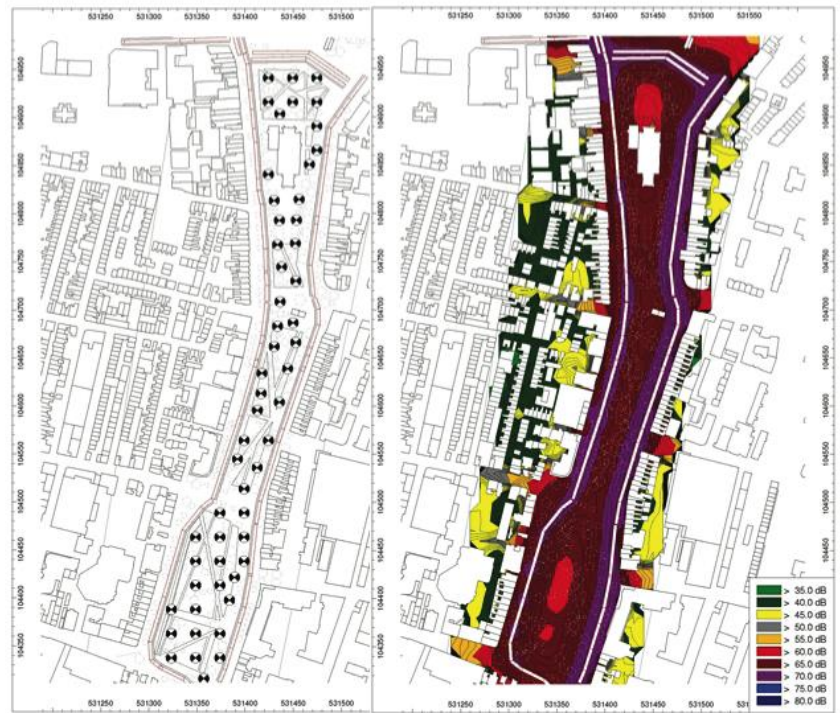

Figure 14: Valley Gardens. Identification of receiver points (left). $\mathrm{L}_{\text {den }}$ values with updated traffic data (right).

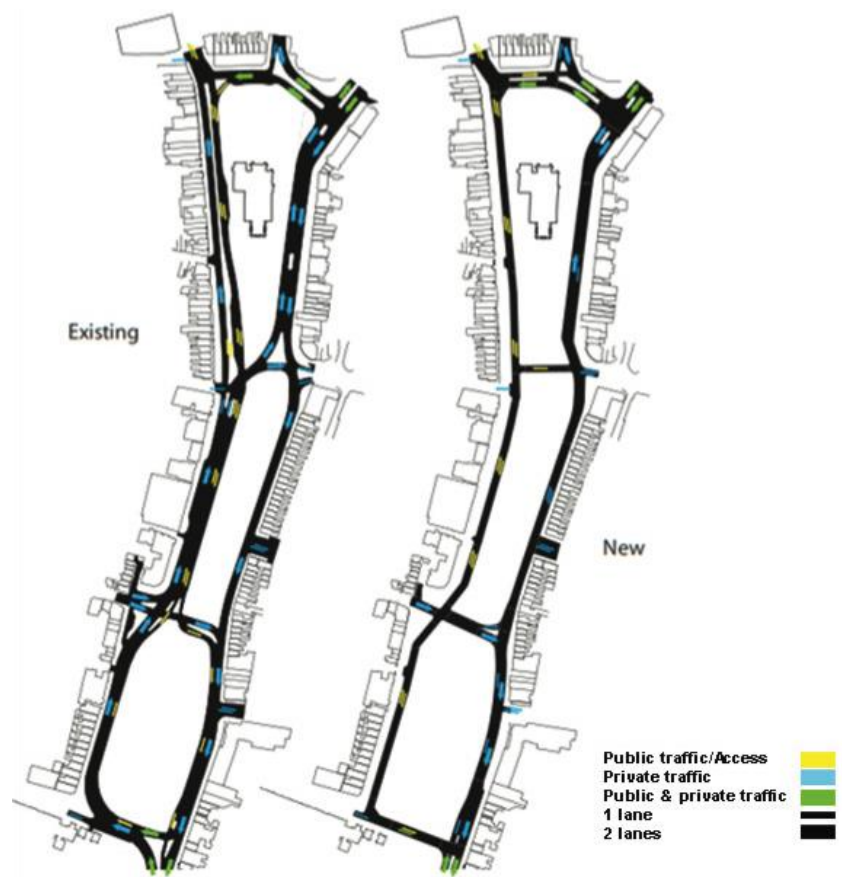

Figure 15: New traffic model for Valley Gardens (courtesy of Brighton \& Hove City Council).

A good acoustic characterisation of current Valley Gardens' situation will constitute a solid background for future proposals and design suggestions.

A detailed road traffic noise map was produced for Valley Gardens. This was performed by the ESRs working group, making use of the most recent road traffic data provided by the Brighton \& Hove City Council, representing the current situation of traffic noise. Fifty-five receiver
Table 2: Proposed and tested noise mitigation actions.

\begin{tabular}{cc}
\hline Case & Action \\
\hline 1 & No reflections from buildings \\
2 & Speed limit set to $20 \mathrm{~m} / \mathrm{h}$ \\
3 & Absorbent noise barrier around the park \\
4 & No heavy vehicles \\
5 & Buses on the West bound and remaining traffic on \\
6 & the East bound \\
\hline
\end{tabular}

points were selected within the study area in order to generate the noise map $\left(\mathrm{L}_{d a y}\right)$, calculated according to the CRTN method and modelled with the noise prediction software CadnaA (version 4.4.145) (see Fig. 14).

In order to mitigate the negative effects of traffic noise, the City Council plans to revise the current traffic layout by changing the width of some lanes and moving the private traffic to the East bound, leaving public traffic on the West bound (see Fig. 15). Such actions are likely to have significant impacts on the sound environment of Valley Gardens. Therefore, these scenarios, as well as other possible scenarios, were modelled.

A number of noise mitigation actions have been proposed in order to assess potential benefits of an overall solution aimed at improving the Valley Gardens sound environment. Six general cases were considered, for which the main actions are summarised in Table 2.

The six cases were tested in the updated noise map and the results are shown in the following (Fig. 16). These results are being worked and discussed with the City Council.

Regarding the characterisation of the sound environment, a combined noise survey and soundwalk campaign was carried out at eight selected locations close and within the Valley Gardens; namely: 1. Seafront, 2. The Old Steine, 3. Royal Pavilion, 4. Victoria Gardens South - Victoria Statue, 5. Victoria Gardens South - Mazda Fountain, 6. Victoria Gardens North, 7. St Peter's Church and 8. The Level.

A sample of 21 participants from the SONORUS Consortium took part. Participants were led by an experimenter walking across the study area and stopping at the eight selected locations. For each location, participants were asked to listen to the acoustic environment for two minutes and to fill in a structured questionnaire. The questionnaire [27] included questions about: participants' demographic information, expected social or recreational activities, noticeability of different sound sources' types, perceptual attributes' semantic scales related to the sound 


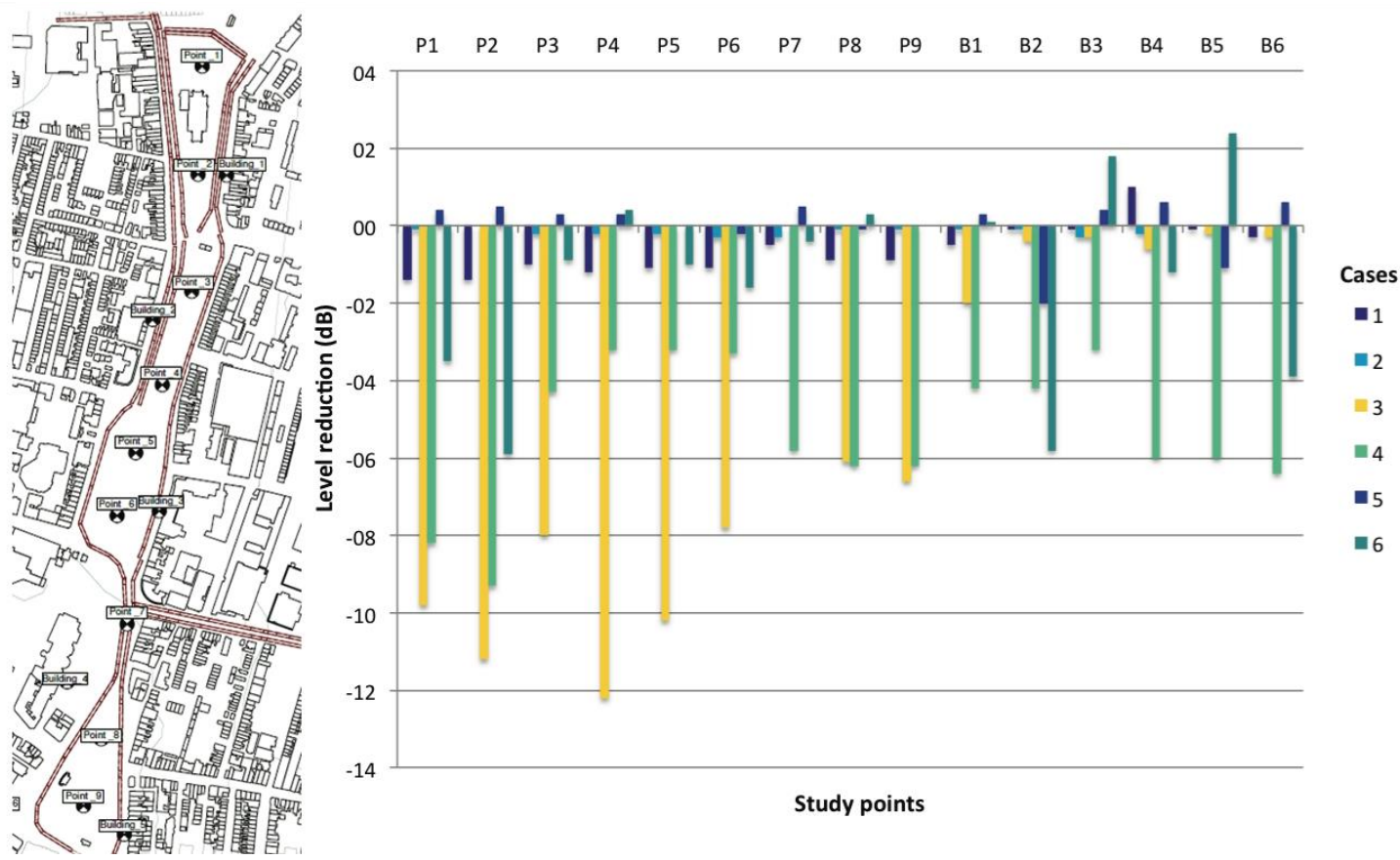

Figure 16: Results of different scenarios suggested by the working group at different random points within the park (points P1 to P9, from top to bottom) and building facades (points B1 to B6, from top to bottom).

environment and overall quality and appropriateness of the sound environment. Two sets of questions were further considered for the work with the City Council:

- Soundscape quality:

- "Overall, how would you describe the present surrounding sound environment?"

- "Overall, to what extent is the present surrounding sound environment appropriate to the present place?”.

For both questions, a ten-point scale was used, ranging from "very bad" (0) to "very good" (10) for Q1, and from "not at all” (0) to "perfectly” (10) for Q2.

- Sound sources profiles:

"To what extent do you presently hear the following five types of sounds?”

- Traffic noise (e.g., cars, buses, trains, airplanes)

- Other noise (e.g., sirens, construction, industry, loading of goods)

- Sounds of individuals (e.g., conversation, laughter, children at play)

- Crowds of people (e.g., passers, restaurants, sports event, festival)

- Natural sounds (e.g., singing birds, flowing water, wind in vegetation)
For this question, a ten-point scale was used, ranging from "do not hear at all" (0) to "dominates completely" (10).

While participants were filling the questionnaire, an operator carried out sound-pressure level measurements by means of a calibrated sound level meter. Overall results are presented below (Figs. 17 and 18).

With the data collected during the soundwalk, a "sound sources' dominance map" was also produced by implementing the mean individual scores for the sound sources profiles question into a Geographical Information System (GIS) platform and generating a prediction surface for the study area through the 'kriging' interpolation method [27] (Fig. 19).

From these maps it can be observed that road traffic noise sources dominate the area and that "sounds of crowds" and "sounds of individuals" had low scores, which suggests the absence of human activities throughout the park. This area is not considered to be a place to go for outdoor leisure or gathering activities [27].

A different soundscape strategy was also proposed, aimed at achieving attentional auditory masking for hot spots where traffic noise reduction is not easily feasible. The sound-pressure level of a walking sound on a platform covered with gravel was compared with a 15-second excerpt of traffic noise recorded at a crossroad in Valley Gardens. This was performed with the idea to show that 


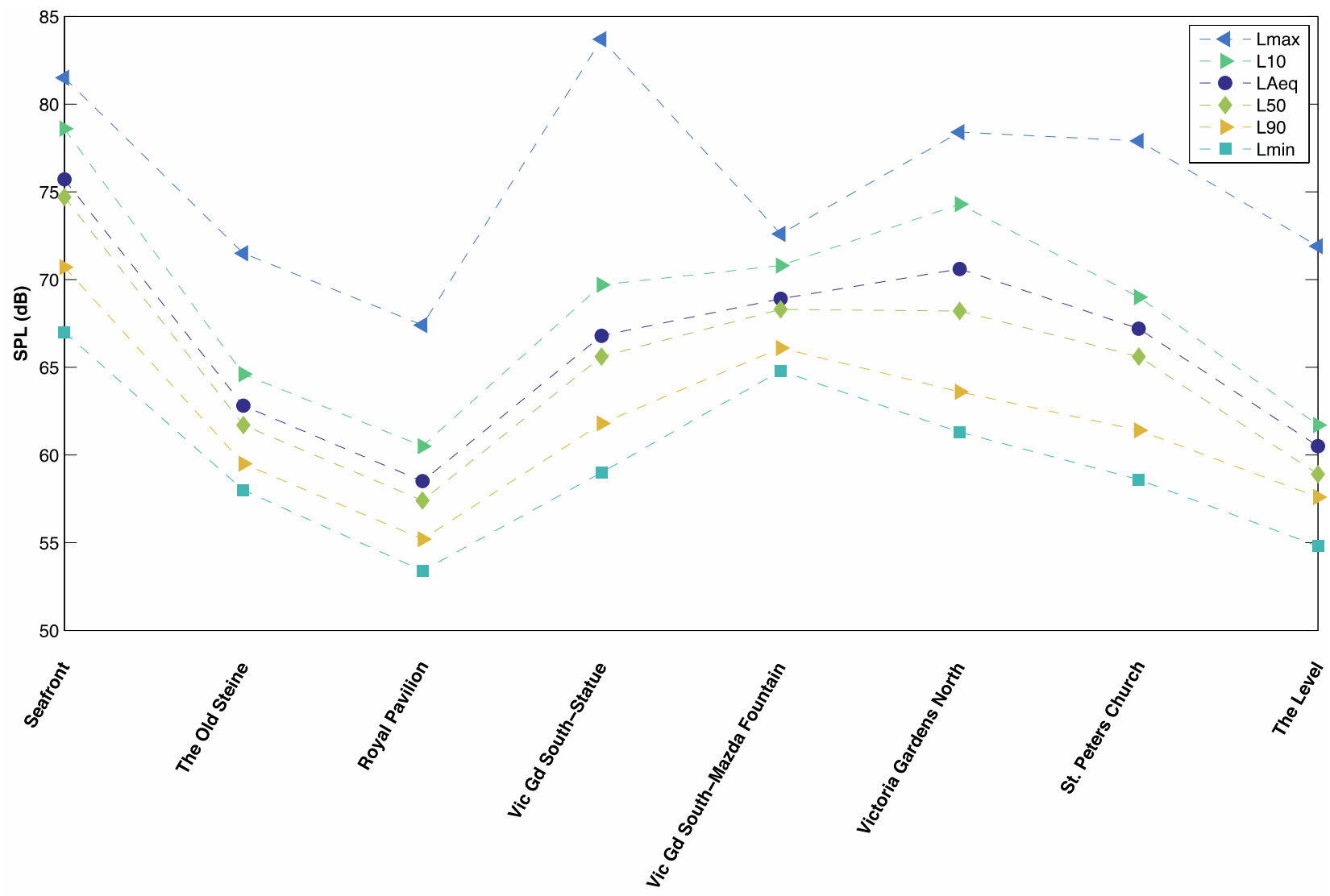

Figure 17: Sound Pressure Level at the 8 selected points along Valley Gardens.

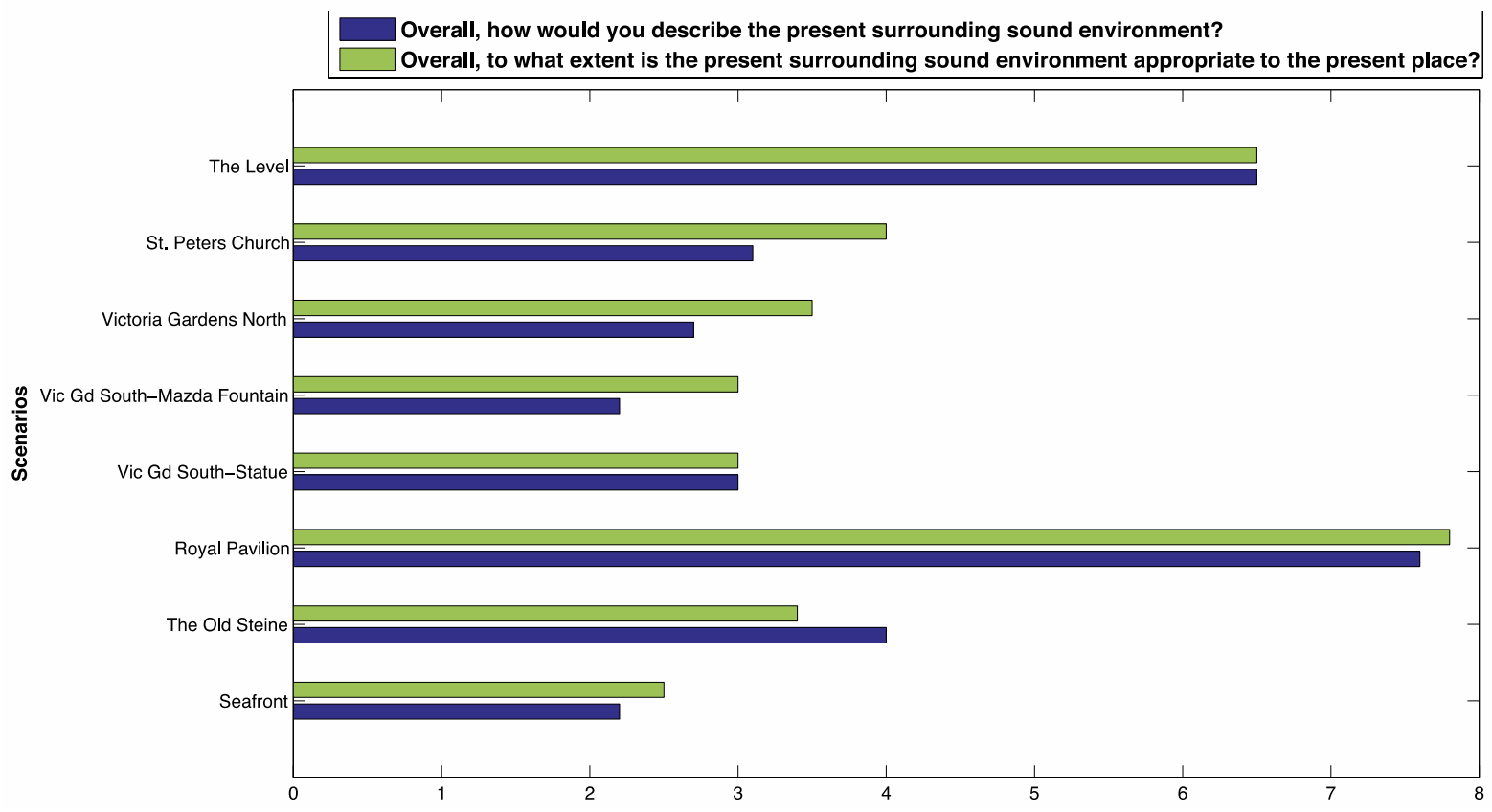

Figure 18: Median individual responses for appropriateness of the sound environment to the place (ranging from 0 "not at all appropriate" to 10 "completely appropriate") and overall sound environment quality (ranging from 0 "very bad" to 10 "very good"). 

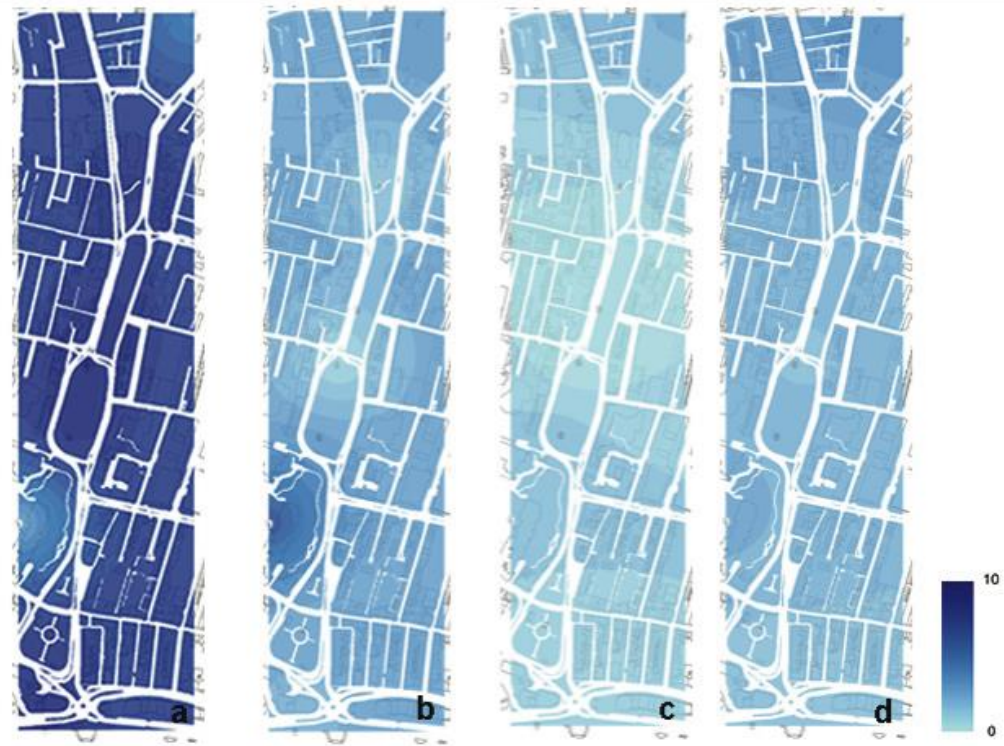

Figure 19: Sound source dominance map: Traffic (a), Natural sounds (b), Sounds of crowds (c), Sounds of individuals (d) - extracted from [27].

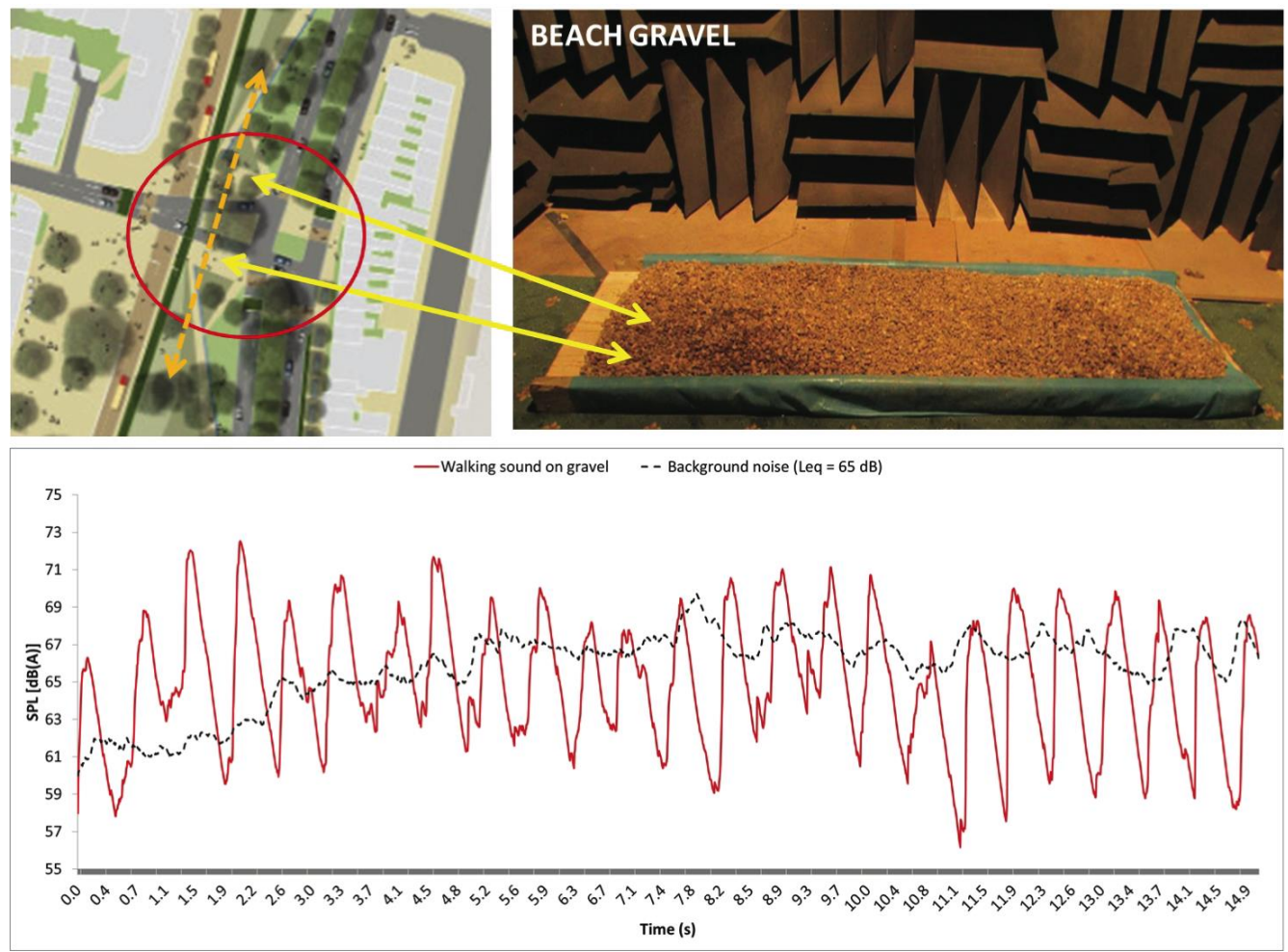

Figure 20: Results of masking effects of proposed solution.

such a passive sound source could help reducing the perceptual effects of traffic noise. A simulation of the comparison between the walking sound on gravel and a typical background noise recorded on site during the soundwalk is shown in Fig. 20. Even though the masking effec- tiveness of the walking sound from gravel should be further assessed with subjective tests, the time history in Figure 20 shows that the walked on material's sound level has the potential to exceed a typical road traffic noise as recorded on site. Therefore, it seems reasonable to assume 
that this solution could provide energetic as well as attentional masking for the unwanted sound source.

Data collection in the test site (both objective measurements and individual responses) confirmed that road traffic noise is the most relevant noise source while being perceived as inappropriate to the Valley Gardens area. Therefore, several traffic scenarios proposed by city planners were tested and calculations showed interesting results, which will be considered when deciding for a final traffic situation. As a complete soundscape characterisation of the site is available, the future Valley Gardens will integrate not only the noise levels perspective but will also support the planning of acoustic restoring areas. Other actions include reducing noise at source and improving source-receiver environment. Cases 1-6 exemplified this approach and included actions to avoid noise generation (e.g. different traffic planning), to reduce noise levels at source (e.g. traffic calming measures) and to improve source-receiver environment (e.g. noise barrier).

\subsection{Gothenburg: Frihamnen area}

\subsubsection{General description}

Located at the mouth of the river Göta, Gothenburg is the second largest city in Sweden, with around 550,000 inhabitants in the urban area, and is mainly composed by the mainland and the island of Hisingen, making a frame for the river.

The area called Frihamnen (Free port) is the third test site of the SONORUS project. Built in the twenties as Gothenburg's most inner harbour, it is situated on the north bank of the river in a former industrial zone in Hisingen. This area (see Fig. 21) is on the way to be transformed into a dense and mixed-use neighbourhood, becoming one of the biggest urban planning projects in Gothenburg City Centre.

It worked as a Free Port until 1996 and has been historically considered a strong link between the mainland and Hisingen. As such, it has been supporting while suffering several transformations as part of Gothenburg's maritime and industrial past, leading the area to an undefined situation (see Fig. 22) holding sporadic concerts, sports and social events.

Frihamnen is framed in the river bank city vision (Älvstaden) with the intention to build a more cohesive, inclusive, green and dynamic city open to the world. Under this long-term planning process, by 2040, Frihamnen area will hold 15,000-20,000 residents and as many workplaces. In 2021, Gothenburg will celebrate its 400-year anniversary,

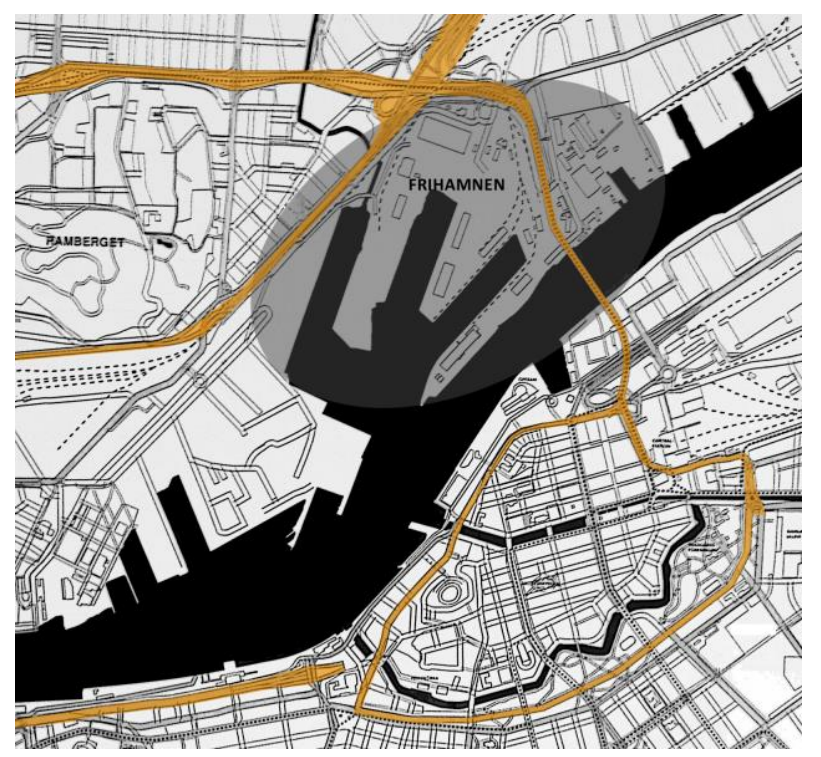

Figure 21: Gothenburg city and Frihamnen area.

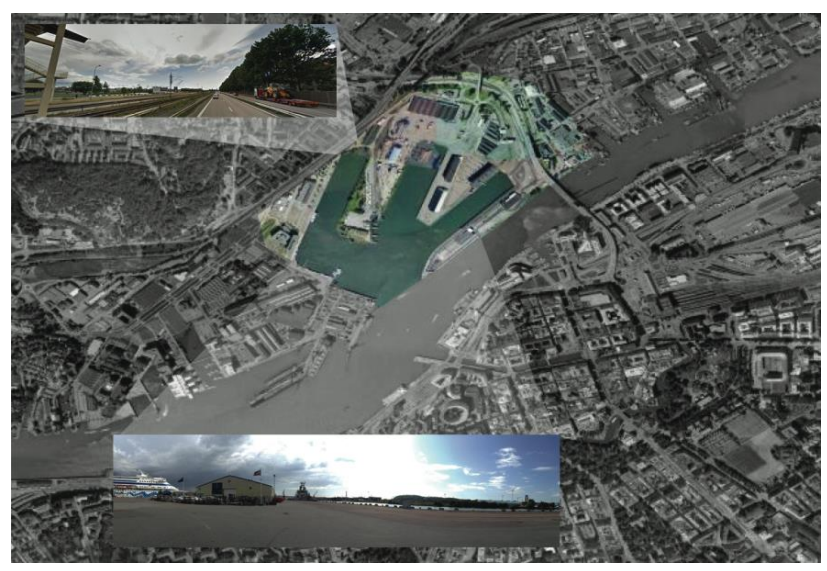

Figure 22: View of Frihamnen area.

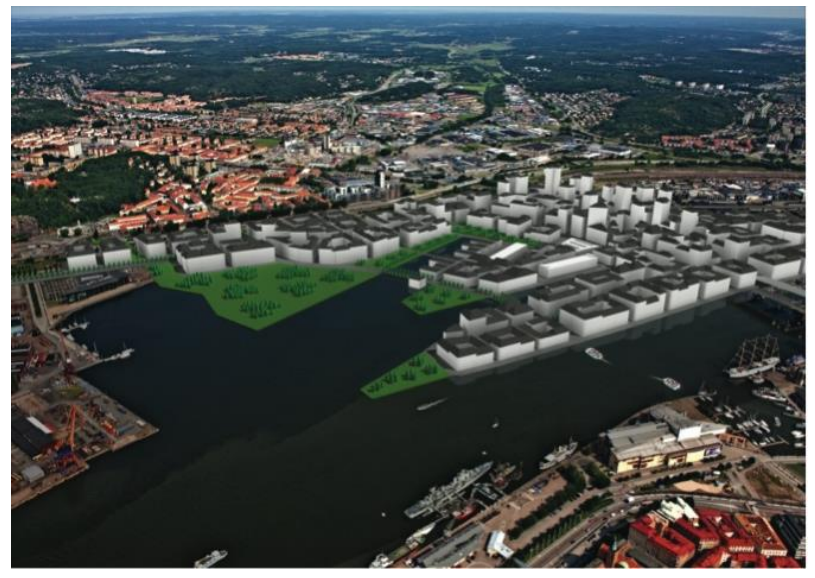

Figure 23: Preliminary Frihamnen vision for 2040 (provided by Frihamnen working group from the city). 

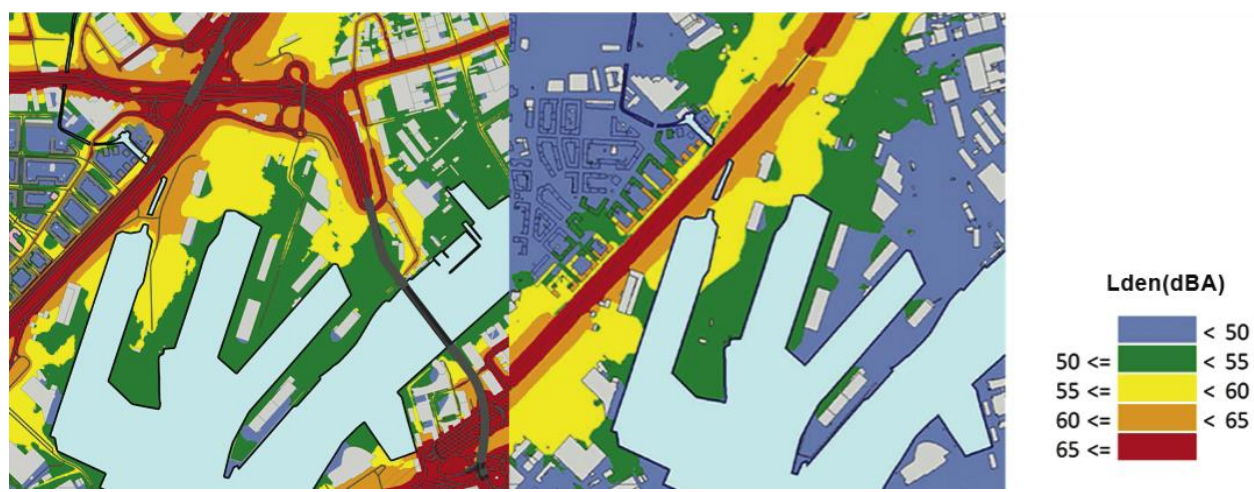

Figure 24: $\mathrm{L}_{\text {den }}(\mathrm{dBA})$ according to Swedish noise descriptor at Frihamnen area taken from the Noise maps, Göteborgs kommun published in 2015 [29]. Road traffic and tram (left), railway traffic (right).

and by then, Frihamnen is going to allocate a commemorative park, 1,000 houses and the same number of working places [28]. At the time, the overall structure is determined, however, the entire planning is under a constant development and nothing has been decided yet in detail (Fig. 23).

\subsubsection{Specific challenges}

Today, Frihamnen area is exposed to various noise sources. Road traffic is dominant mainly due to two major road infrastructures located towards north and east. Moreover, there are several streets that serve as connectors around the area. Also, a busy railway track in the northeast leads the trains to the outer harbour. This overall layout conducts the area into an almost non-existent connection to the city, as it is reflected towards the northeast, were beyond the impenetrable division of around $50 \mathrm{~m}$ of railroad tracks and highway (see Fig. 22), one can find Keiller's Park and Ramberget, a popular hill in the city.

Despite the multitude noise sources (see Fig. 24), the acoustic environment at Frihamnen area will be substantially influenced by the future development on the riverbank, changing its structure with respect to population, business, transportation, etc.

In addition, different planning aspects are divided between several authorities. Key players are the company "Älvstranden Utveckling AB", the council of Gothenburg with the offices of traffic (trafikkontoret), real estate (fastighetskontoret) and environment (miljökontoret), as well as the Swedish road and rail authority (trafikverket).

Regarding the acoustic environment, Gothenburg has developed the Noise Action Plan for 2014-2018 [30]. One of its ambitious objectives is focused on residents, where by 2020 , at least $95 \%$ of the population should be exposed to noise levels lower than $60 \mathrm{~dB}\left(\mathrm{~L}_{A E q, 24 h}\right)$ at the most ex- posed façade. As a first step, compensatory measures and building design adaptations are persuade. However, the focus is on a long-term perspective, where acoustic environment is included in three main city strategies: planning development, transport and a dense green city. The previous may conflict with current plans and actions in the city, neglecting the interaction between the diverse sociotechnical-ecological systems involved in urban planning processes, affecting the environmental quality and therefore, the livability of spaces. Within this framework, it is inevitable to recognize the need of tools to enable the integration of urban sound planning in the new urban development.

\subsubsection{Integration of urban sound planning}

Frihamnen presents a complex situation with a great potential to become a pleasant area, but on the other hand, it holds several environmental and infrastructure problems as unstable and contaminated ground, noise and air pollution, and the omnipresence of major transport infrastructures. In this sense, transforming the area with the aim of creating a dense/mixed-use neighbourhood, will add a huge pressure in terms of traffic demands and community needs, most likely, increasing the amount of road traffic inside the area as well as its surroundings, impacting the city transportation model.

As part of the work carried out in SONORUS, a dynamic tool assessment to study the transportation system and its effects on Frihamnen acoustic environment is under development, where its first stage was presented at [31]. The work is mainly dedicated to the transportation system and the possibilities to improve its acoustic quality. Transport system is considered a key in the holistic approach due to the multiple consequences it has in other systems, gener- 

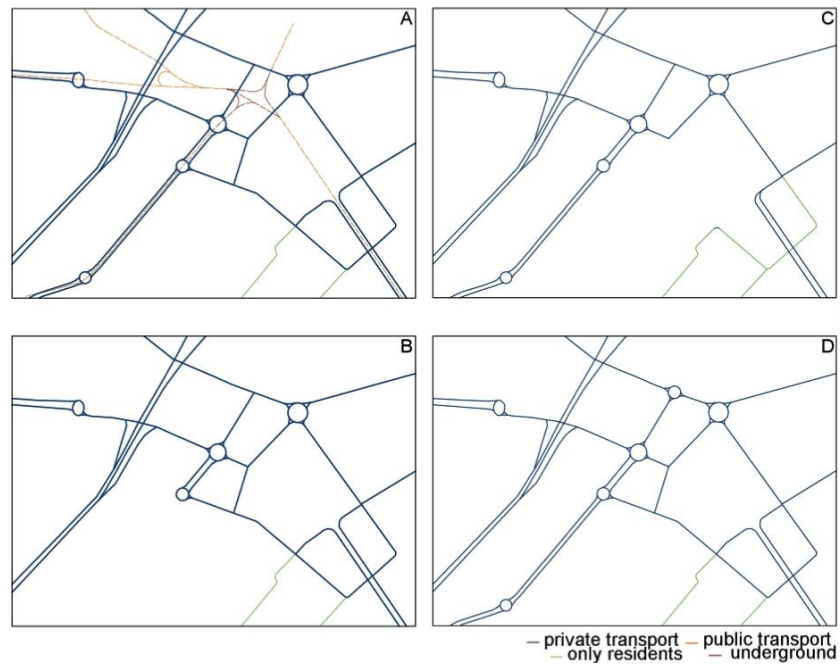

Figure 25: Traffic strategies scenarios (extracted from [31]).

Table 3: List of studied scenarios (extracted from [31])

\begin{tabular}{|c|c|c|}
\hline Scenario & Description & $\begin{array}{l}\text { Model } \\
\text { layout }\end{array}$ \\
\hline 1 & Base scenario with adaptations & A \\
\hline 2 & $\begin{array}{l}\text { Remove parallel road to highway } \\
\text { E155 }\end{array}$ & B \\
\hline 3 & Remove roads close to piers & $C$ \\
\hline 4 & $\begin{array}{l}\text { Transform intersection with lights } \\
\text { into roundabout }\end{array}$ & D \\
\hline 5 & Reduce speed on E155 to $50 \mathrm{~km} / \mathrm{h}$ & $A$ \\
\hline 6 & Reduce speed on bridge to $50 \mathrm{~km} / \mathrm{h}$ & A \\
\hline 7 & $\begin{array}{l}\text { Reduce speed on road close to piers } \\
\text { to } 30 \mathrm{~km} / \mathrm{h}\end{array}$ & A \\
\hline 8 & $\begin{array}{l}\text { Remove medium-heavy and heavy } \\
\text { vehicles }\end{array}$ & A \\
\hline 9 & Acceleration set to 0 & A \\
\hline
\end{tabular}

ating a cascade effect capable to improve or decrease the quality and livability of an area.

In this tool, the study here is focus on developing four scenarios and nine alternatives to the preliminary traffic planning from the traffic office (Table 3 and Fig. 25). The intention is to help in the evaluation of the future acoustic environment in connection with its traffic demands. These scenarios were chosen to attend the possibilities of the area and plausible acoustic capacities it can hold in terms of quality of spaces (closeness to water, interaction with major infrastructures, location of residential areas, etc.)

The dynamic tool was performed with a microscopic traffic simulation including vehicle kinematics, which holds a strong influence in vehicles noise emission. This simulation gives output data such as location of vehicles,

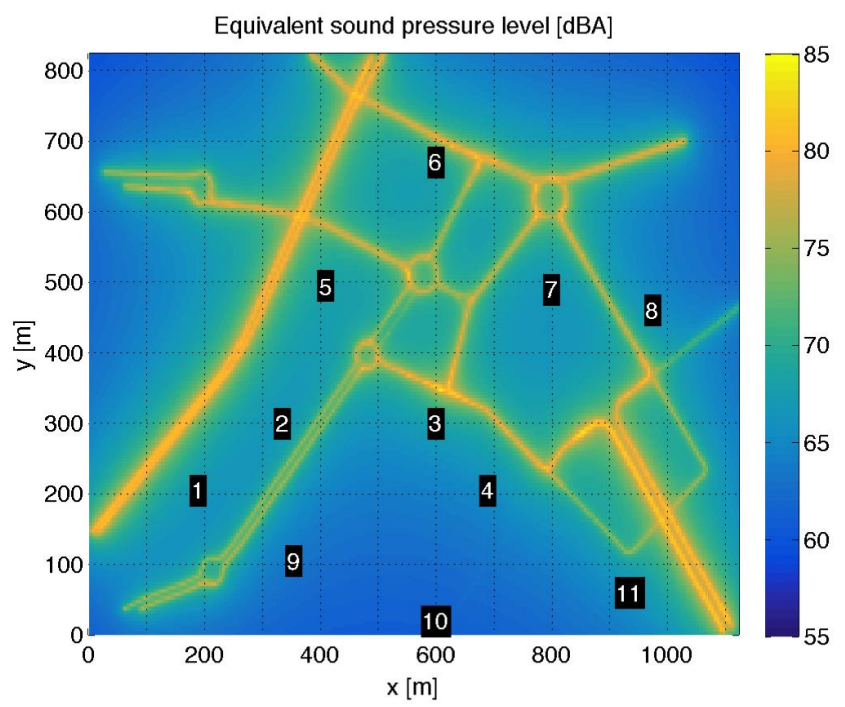

Figure 26: $\mathrm{L}_{A e q, 900 s}(\mathrm{~dB})$ for base scenario.

speed and acceleration of each of them, going far beyond from the traditional static traffic flow analysis used in noise mapping calculations. The tool integrates a number of scripts developed in Matlab that take as input the data from the microscopic traffic analysis performed through the software Vissim (PTV Vissim 6.0), obtaining the acoustic characteristics of the considered scenarios through the CNOSSOS emission model [22]. For it, the worst plausible situation of traffic demand is simulated. As an example, Fig. 26 shows the noise map of the base scenario with 11 study points.

An interesting analysis in this type of tool is the possibility to understand the equivalent sound pressure level $\mathrm{L}_{\text {Aeq,900s }}$ that each road segment contributes to a certain study point, being this a kind of contribution noise map. For example, comparing the base and second scenario (removing road parallel to highway) for study point 9 , there is a reduction in $\mathrm{L}_{\text {Aeq,900s }}$ by around $2 \mathrm{~dB}(\mathrm{~A})$ and in $\mathrm{L}_{\text {peak }}$ by $3 \mathrm{~dB}(\mathrm{~A})$. Fig. 27 shows noise contribution from the road segments for the previous two cases.

The next figure (Fig. 28) shows scenarios 1 (base) and 3 (roads close to the piers are removed). Here, indicators LA50 (dB) and LA10 (dB) are compared for both scenarios in all study points. The results show that for five of the study points, the change to scenario 3 reduces the events above LA10; for the rest, the effect is the opposite. Similar results happen with LA50 indicator. In study point 3, the number of events is remarkable, 47 in the first scenario, which is located next to a signalised intersection. In the case of $3^{\text {rd }}$ scenario, the number of events is reduced to 4. This has consequences in other study points, increasing the events most probably due to the increment in the 

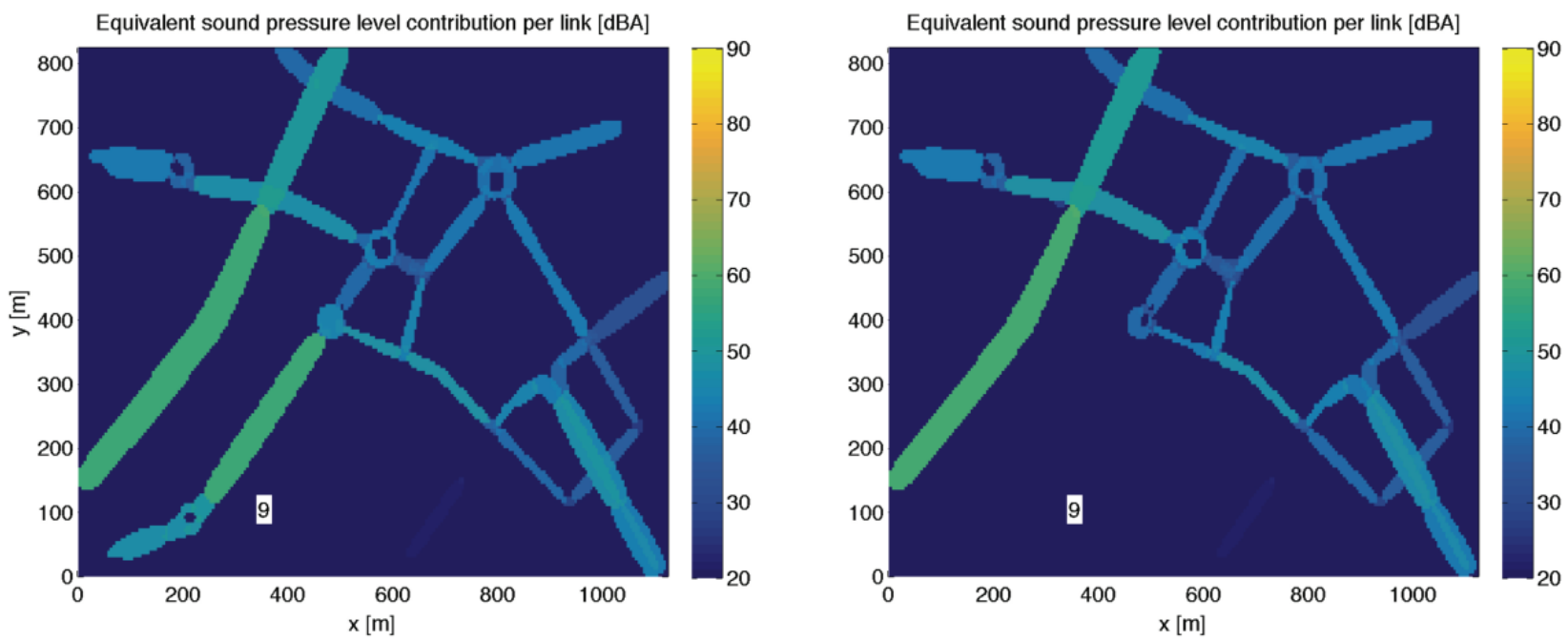

Figure 27: Contribution maps for traffic strategies. Base scenario (left). Second scenario (right).

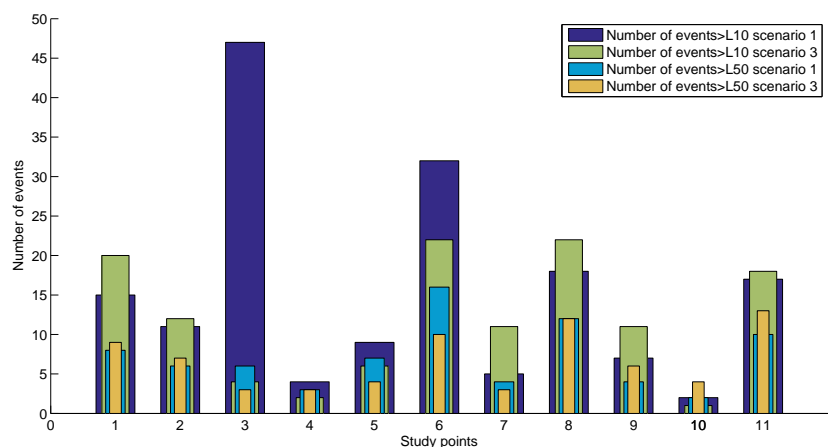

Figure 28: Number of events above LA10 and LA50 (dB) in scenarios 1 and 3 for all study points.

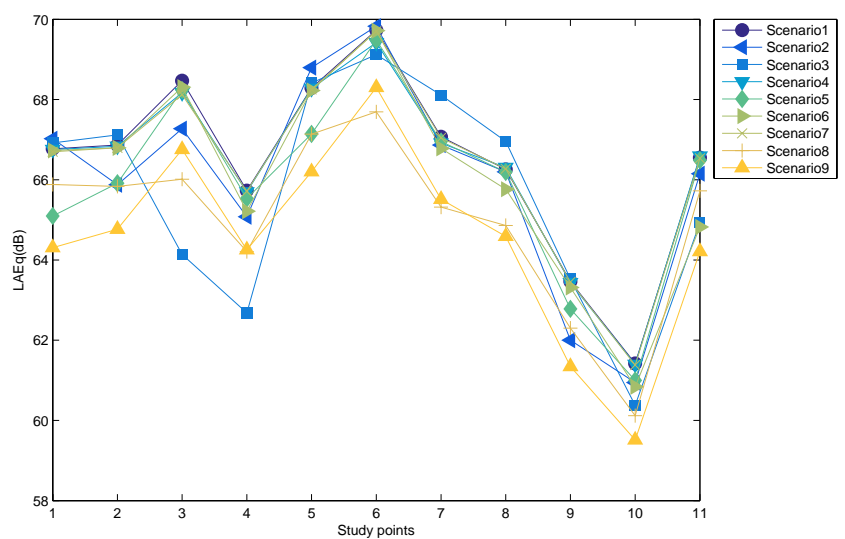

Figure 29: $\mathrm{L}_{A E q, 1 h}(\mathrm{~dB})$ in all study point at all scenarios.

number of vehicles through other roads. This type of analysis is interesting in the sense of setting acoustic qualities and needs to different space configurations, helping in the development of further steps in terms of annoyance and number of events.

As another example of the possibilities the tool has, Fig. 29 represents the equivalent sound pressure level $\left(\mathrm{L}_{A E q, 1 h}\right)$ in all study points for all scenarios, indicating the difference in terms of noise emission due to different road traffic disposition.

The results show that some of the tested scenarios could in fact improve the future acoustic situation of the area depending on the acoustic qualities, its functions and uses. Here, the inclusion of a real scenario allows the planning of real traffic situations, where noise contribution maps and time patterns may help to understand the consequences of urban planning processes in the acoustic environment. Further information about this study can be found at [31].

Frihamnen project is now in the process to match the proposed vision and the project it will become. That situation is demanding an anticipatory process through a holistic approach with a strong multidisciplinary collaboration. The research conducted within SONORUS at Frihamnen area is looking for different possibilities to improve the acoustic quality of spaces, where such tools and outcomes can enhance an integrated urban development process. There is a risk that the whole area will confront even higher noise levels than the current ones. Moreover, the risk is on ignoring the appropriateness of the acoustic environment to the space uses and functions, denying the opportunity to allocate different acoustic capacities that pursue a certain acoustic environment. 


\subsection{Rome: Colosseum, Palatine and Roman Forum area}

\subsubsection{General description}

Rome is one of the most populated cities in Europe and it is best known for its historical and archaeological heritage. The tourism as an approach to cultural and historical richness of a city, promotes the emergence of new strategies of heritage interpretation. These strategies are aimed at enhancing the identity of the sites and improve their livability.

The Flavian Amphitheatre (Colosseum) and the Roman Forum form a vast archaeological area in the centre of the City of Rome, one of the most important archaeological sites in the world, which is enjoyed by more than 6 million visitors per year [32] (Fig. 30).

The area is under the National Monuments and Archaeological/Historical sites Authority. In the area, construction activities are currently on-going for the "Fori Imperiali" station of the new metro line.

The area is inserted in the urban structure of Rome, with busy roads in the perimeter and a high anthropic activity. It has been included (see Fig. 31) in the so-called first acoustic class (highly protected environments where the quiet is a basic characteristic for their use: hospitals, schools, areas for resting and recreational purposes, residential rural areas, parks, etc.) [33].

According to the acoustic zoning, the noise limits in force are shown in Table 4.

Despite these limits, the sonic environment seems not suitable to improve the enjoyment of visitors, due to the road traffic flow (2000-2500 veh/h with 15\% heavy vehicles) responsible for levels above $65 \mathrm{~dB}(\mathrm{~A})$ of LAeq quite often present in the area. This levels are much higher than the quality objectives for the day period of the Italian Legislation, established in $47 \mathrm{~dB}(\mathrm{~A})$ [35]. Although the legislation requirements are difficult to achieve, the municipality of Rome has been undertaking some actions in recent years in order to reduce the levels of noise, like banning private traffic in a stretch of Fori Imperiali street (green line in Fig. 32) and along the northern side of Colosseum.

As an example, Table 5 shows the reduction of traffic flow observed between 8:00-9:00 h. at weekdays after the traffic restrictions (data provided by Roma City Hall).

Further changes in the mobility are planned due to the working areas of the new underground line, which are in progress and will affect the acoustic environment.

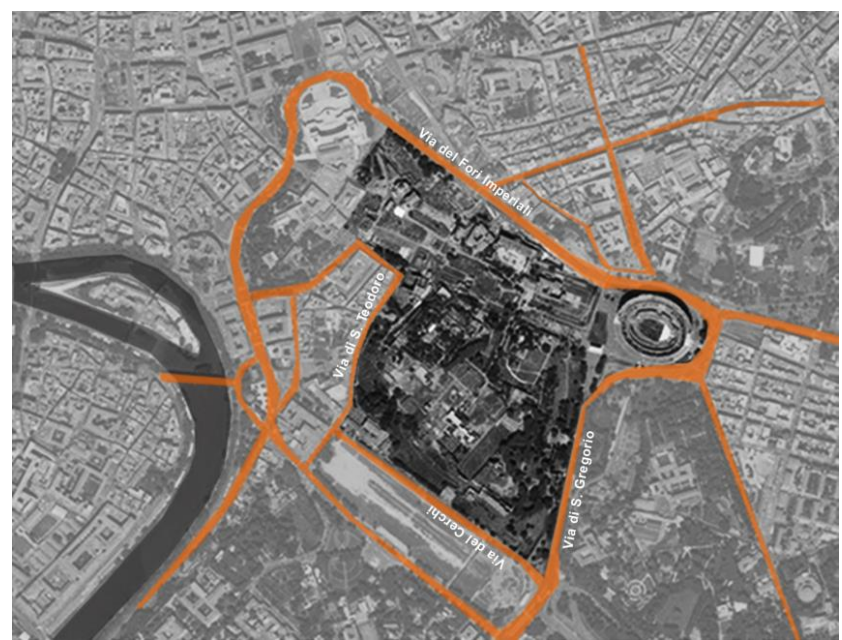

Figure 30: View of the Archaeological/Historical area.

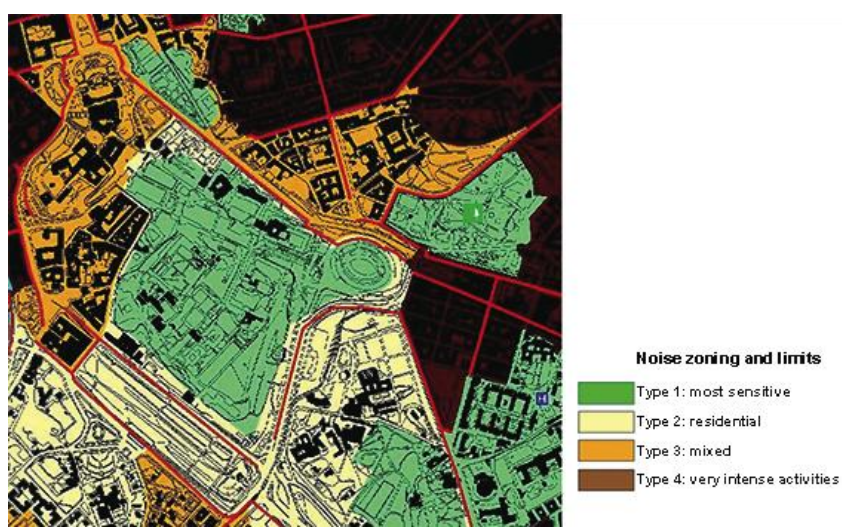

Figure 31: Acoustic classification of the Archaeological/Historical area [34].

Table 4: Noise limits in $\mathrm{dB}(\mathrm{A})$ for the 1st class acoustic area [35]

\begin{tabular}{ccc}
\hline Limit values & Day-time & Night-time \\
$\mathrm{L}_{\text {Aeq }}[\mathrm{dB}(\mathrm{A})]$ & $6: 00-22: 00$ & $22: 00-06: 00$ \\
\hline Immission & 50 & 40 \\
Emission & 45 & 35 \\
Quality & 47 & 37 \\
\hline
\end{tabular}

\subsubsection{Specific challenges}

Several challenges were set in order to protect, conserve, understand and value the archaeological complex:

- from a wide perspective, improving the quality and attractiveness of the outdoor spaces;

- balancing the need for protection of the remains with allowing maximum access to them; 


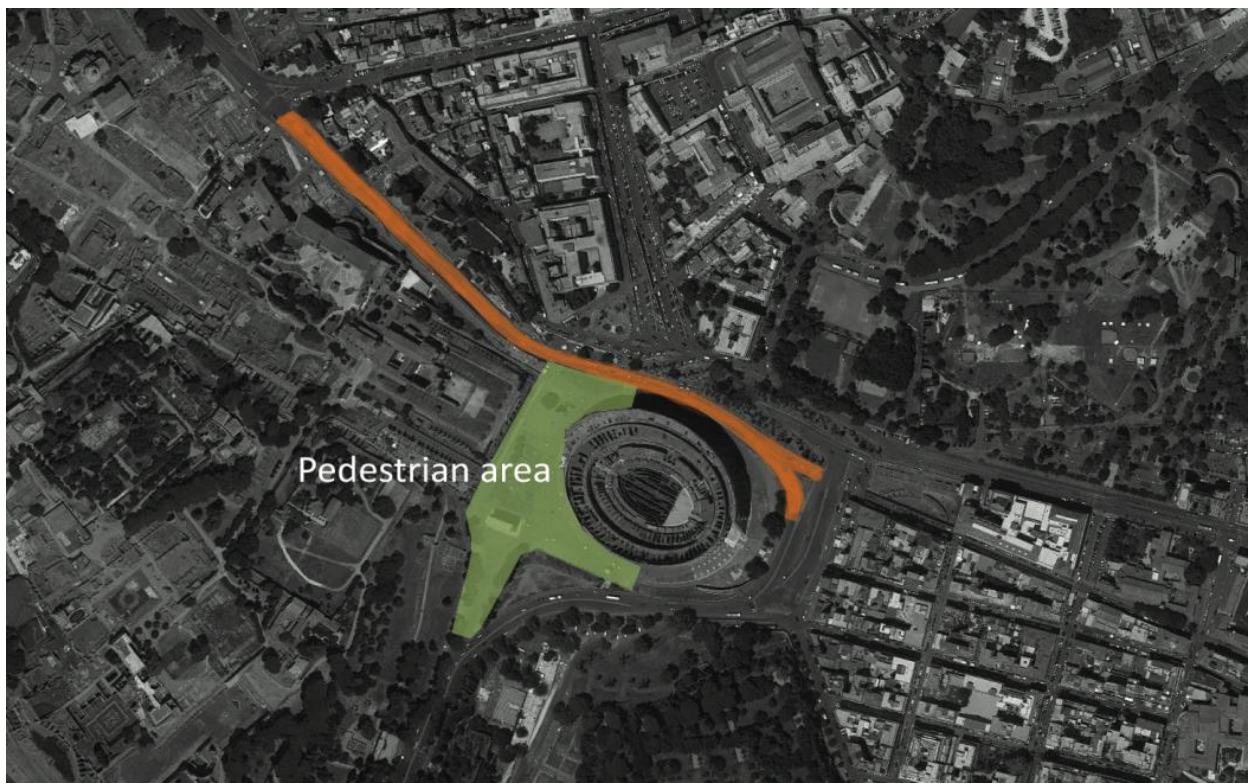

Figure 32: Restrictions of road traffic in the Archaeological/Historical area.

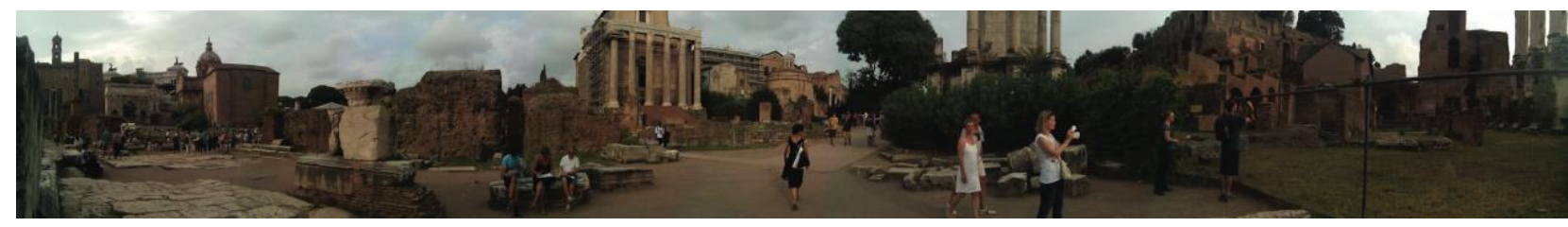

Figure 33: Panoramic photograph inside the Roman Forum.

Table 5: Traffic flows before and after the private traffic restriction in the Fori Imperiali Street.

\begin{tabular}{ccc}
\hline Traffic type & \multicolumn{2}{c}{ veh/hour } \\
\cline { 2 - 3 } & Before & After \\
\hline Private & 1295 & 0 \\
Buses & 62 & 62 \\
Taxis & 560 & 560 \\
Total & 1917 & 622 \\
\hline
\end{tabular}

- ensuring the site's harmonious integration within the town as a significant part of the heritage, fostering the city social, cultural and economic development;

- promoting a participative process, taking into account the expressed or perceived viewpoints of all stakeholders, including all non-specialist individuals and organizations which might rightly have a valid claim to participate;

- from an acoustic point of view, evaluating the factors that can affect the sonic environment of the area.

\subsubsection{Integration of urban sound planning}

Millions of people go every year to Rome with the intention to visit the Colosseum, the Roman Forum and the Palatine. The needs and interests of the tourists should be catered, and the widely increasing requirements be taken into account to reach values of excellence according to the expectations of visitors. On the other hand, noise levels requirements change as society evolves, so the tourist's demands will be also evolving in time. Because of this, the merely intervention is not enough; strategies of monitoring the degrees of satisfaction after the interventions are needed for a continuous improvement in order to reach levels of excellence.

The wide variety of aspects that can affect the satisfaction of tourist's demands requires a multidisciplinary approach to undertake the problems and promote the material and immaterial potentialities of the area. With these particular features, the works has been carried out within a framework of respect for the archaeological and cultural historical values of the area and commitment with the visitors. 

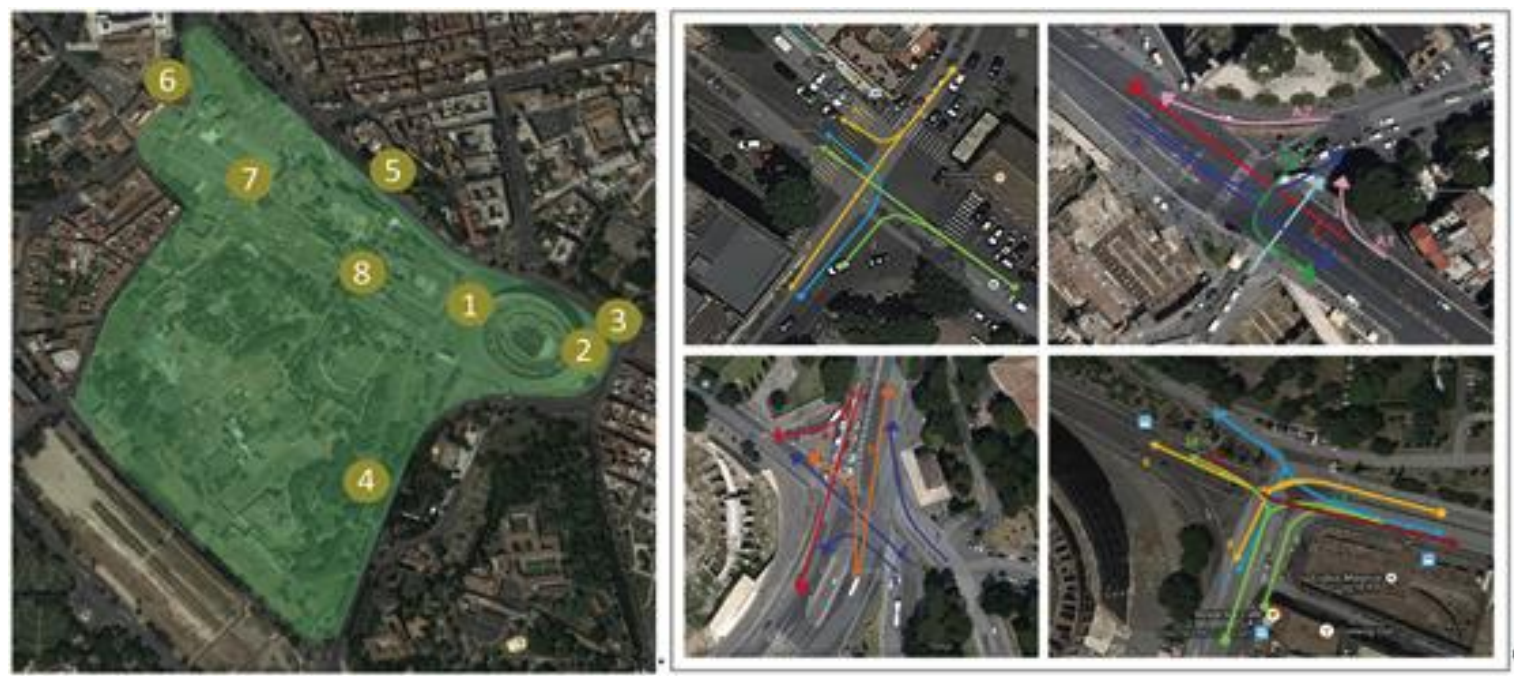

Figure 34: Survey campaign areas (left). Traffic counts and sound measurements points (right).
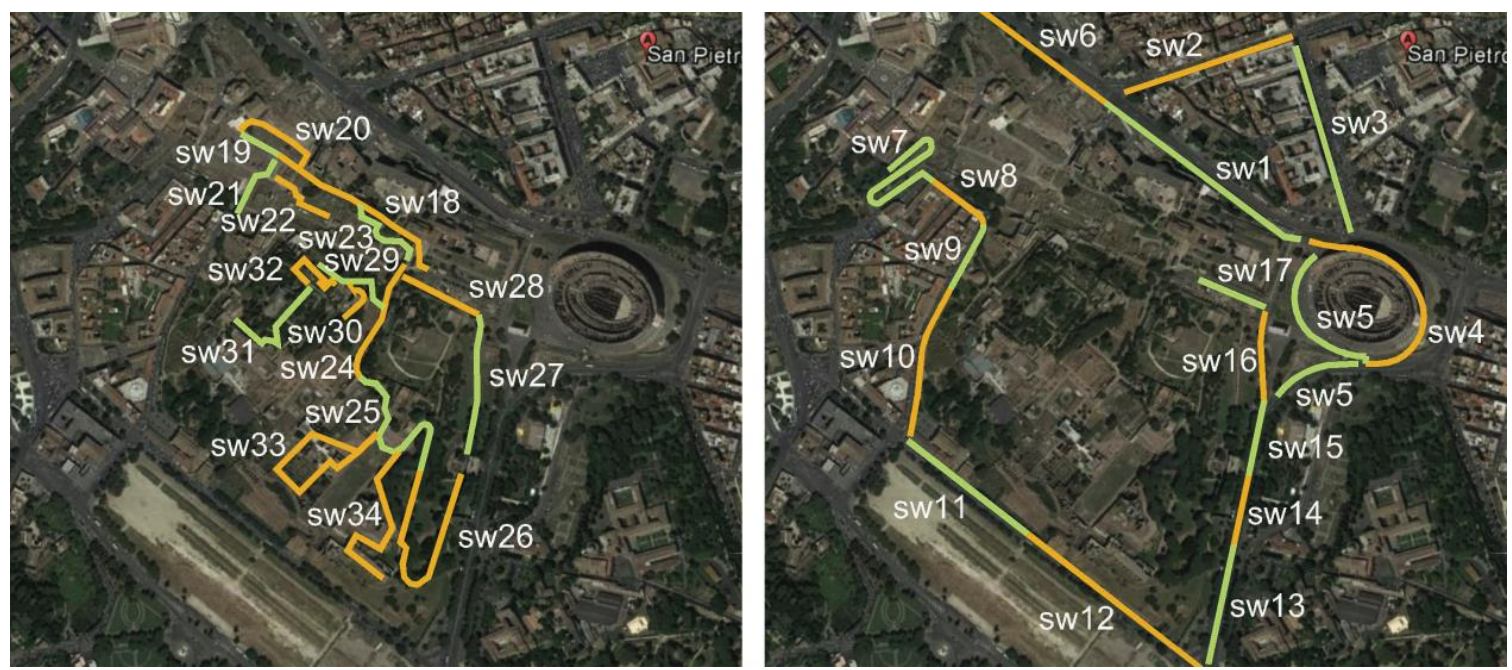

Figure 35: Soundwalk performed inside and outside the area of the Roman Forum and Palatine.

Four phases have been established to achieve the challenges reported in the previous section: 1) Acquisition of data, 2) Data analysis, 3) Conclusions of the analysis, 4) Proposals.

The first phase is being currently developed. It comprises the research on technical and historical literature and the performance of measurements and surveys campaigns. The second phase includes the data processing in order to understand the interleaved layers of reality from technical and psychological points of view: analysing measurements data and surveys campaigns, studying traffic and people flows and preparing sound propagation models of the main sources.

The in situ data acquisition was divided in two campaigns. The first one, intended to study the perception of people, consisted of a field survey and sound measurements inside and outside the Roman Forum and Palatine. The second one had the aim to evaluate the different sources through soundwalks, traffic counts, traffic sound registrations and people density.

For the first campaign and in order to evaluate environments with different perceptual features, the following eight areas were selected to perform the interviews (see Table 6, Fig. 34 and Fig. 35).

The questionnaire used for the interviews contained four main groups of questions, namely demographical, general questions of the area, questions about sounds and questions about visual elements. The questions about appraisal were rated in a seven point Likert scale, from 1 (very bad) to 7 (excellent). For example the interviewees were re- 
Soundscape quality_outside

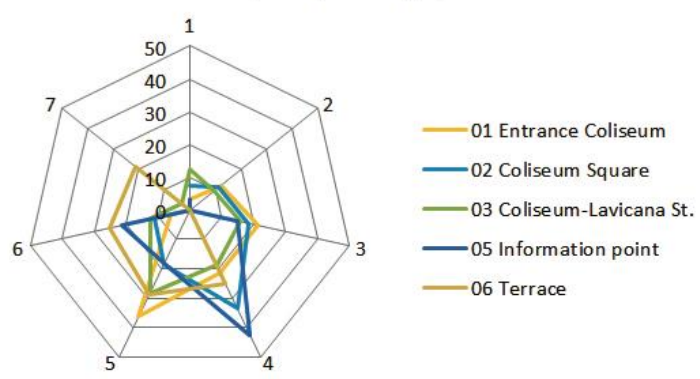

Soundscape quality_inside

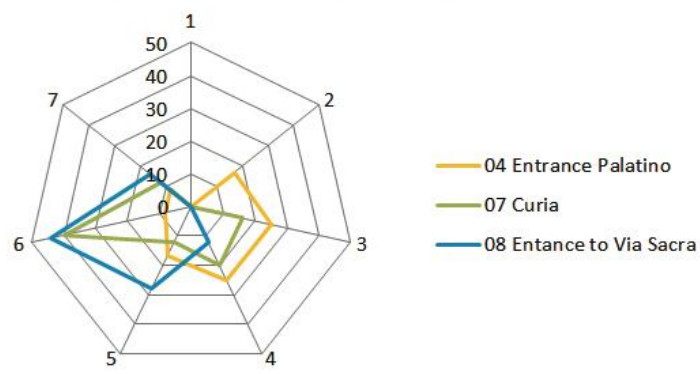

Landscape appraisals_outside

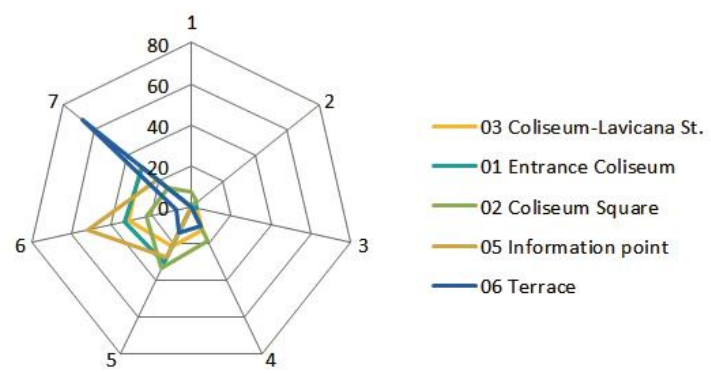

Landscape appraisals_inside

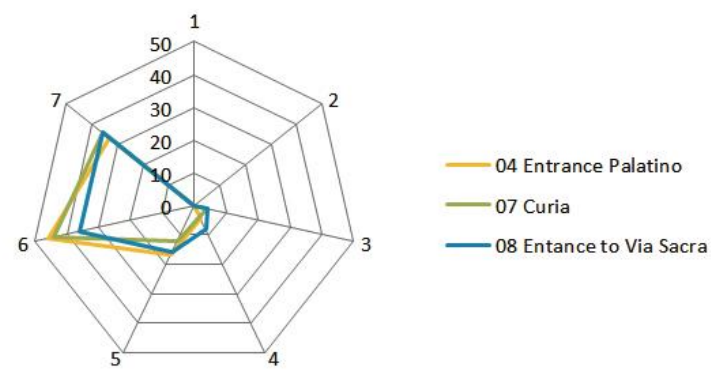

Figure 36: Percentage of subjects that have given a certain score on the soundscape quality (left) and the overall quality (right) of the area (inside and outside of the Roman Forum and Palatine perimeter).

Table 6: Areas of analysis, Rome test site.

1 Entrance to Colosseum

2 Intersection between Fori Imperiali St. and Labicana St. Level of Colosseum Square

3 Intersection between Fori Imperiali St. and Labicana St. Level of Labicana St.

4 Entrance to the Palatine (San Gregorio St)

5 Tourist information point (Zetema)

6 Terrace. Sight of the Roman Forum

7 Curia, Temple of Antonio and Faustina

8 Entrance to Via Sacra. Arch of Tito

quested to give appraisals on the landscape quality, the environmental quality, the soundscape quality, or their overall opinion of the area

While the participants were filling in the questionnaire, 15 minutes of audio recordings and photos were collected (see Fig. 33). The survey campaign was undertaken on weekdays and weekends in July and September 2014, during the visit period of the archaeological complex. During the second campaign, traffic counts were conducted through video registration in fixed positions while photos were taken to calculate people density (Fig. 34). Soundwalks were performed inside and outside the limits of Ro- man Forum and Palatine in order to analyse the distribution of the sound sources (Fig. 35).

Currently, an analysis of the obtained data and a propagation map of traffic noise are under development. Some preliminary results of the subjective data analysis are shown in the Fig. 36. As it was expected, the whole complex is visually very attractive for the visitors. However, the appraisals on the soundscape quality are not always positive. Here, three of the eight areas (areas 1, 2 and 3) under study present a negative mean score. In order to improve their livability, traditional noise control measurements could be taken in areas 2, 3 and 4 with the traffic as predominant sound source. However, voices is the predominant sound source in area 1, where acoustic quality should be tackled from a different perspective, trying to improve the overall impression of tourist or attract their attention in other aspects rather than noise.

As it happens with the landscape appraisal, the general opinion of all the areas is always positive. Nevertheless, the areas with lower general judgments are the ones with lower ratings of the soundscape quality. Correlations will be calculated in future steps in order to verify that this tendency is not just a casualty, and therefore the general opinion of the area is influenced by the soundscape appraisal. 
General recommendations have already been proposed to the municipality in this first stage of the study:

- Reinterpret the identity of the perimeter of the archaeological complex through integrated strategies of regeneration and urban renewal that include the new metro station and the streets Fori Imperiali and San Gregorio, and the Circus Maximus;

- Provide the tourists with general information about the routes within the Roman Forum and Palatine;

- Establish a policy of periodic monitoring of the area through the acquisition of objective and subjective data of the sonic environment.

- Reduce the levels of traffic noise in the perimeter. Pedestrianise the area and vehicle speed reduction, are two possible suggested solutions.

The new proposals for the Rome test site require an integrated vision about the problem of the area. The high noise levels suggest that strategies that go beyond the usual noise control measures are necessary. These strategies can foster the artistic and historic values of the area through enhancing aspects such as information on the set, observation of the landscape or enjoyment of the quiet areas.

\section{Discussion}

This paper aimed to explore the study of the integration of urban sound planning through the practical implementation of the holistic approach in four test sites. A comprehensive and global contextualization of each site supported by approved urban planning methodologies, resulted in innovative acoustic solutions that go beyond the traditional approach. In order to understand the different approaches of this integration, we present a brief discussion on the current and future work that is carried out in each of the sites.

- Antwerp: it is possible to conclude that the noise abatement solutions applied at the source can reach important noise reduction for pedestrians and cyclists up to $5.8 \mathrm{~dB}(\mathrm{~A})$. However, noise abatement solutions applied on the propagation path need to be taken into account as they can have a very strong influence on noise exposure, achieving a reduction of $22.7 \mathrm{~dB}(\mathrm{~A})$. Also, it should be noted that the modelling results have been performed in two dimensions, assuming no variation along the third dimension. They correspond to a 3D model from the section infinitely extruded, which is not a real-life case.
However, they are useful for comparing the efficiency of each noise abatement.

The city representative cooperated with the team and a multidisciplinary approach is included due to the different professional backgrounds of group members. The improvement of urban environments for the citizen's wellbeing is the main concern, considering the acoustic, architectonic, urbanistic and visual experience of the site. Consequently, soundscape study, engineering actions, architectural solutions, urban analysis, traffic models and reorganization of traffic flows have been developed, respecting and enhancing the characteristic identity of each area, consolidating the definition of holistic approach as defined in [7].

- Brighton: the traditional approach provided by the road traffic noise map was extended by including the results of research featuring the overall sound environment characterisation, in both acoustical and perceptual levels, and showed that the sound environment of the site is not adequate to the visitors' expectations. Together, the three tools implemented by the work group (noise maps, sound maps and soundscape maps) proved to be an effective methodology in the analysis stage, as well as in the planning of the future site. It supported the city planners with adequate information to plan urban interventions towards an improved urban solution. The ESR's working group has been working together with city planners to help designing an improved project for Valley Gardens at a relatively early stage in the urban planning process. The main acoustic goal was promoting sound environments that can foster health and wellbeing for citizens. In order to implement the holistic concept, the issues related to the sound environment of the test site were approached both from a conventional noise control and from a soundscape perspective [36].

- Gothenburg: there is a tremendous need to confront the project under a multi-perspective scenario, letting the urban planning process meet the requirements of the city, while offering concrete proposals from a holistic point of view. The ESR's working group has been developing the research in parallel to the development of the project. Our aim is to show different alternatives that can be considered by the city, but also to develop a tool that might be used as part of the design process. In the case of Frihamnen, current and future road traffic is one of the most relevant problems. To study the effects of future road traffic scenarios on the acoustic environment, a dy- 
namic tool is under development, extending the traditional static noise map studies, presenting a dynamic map to assess real scenarios and the different alternatives that can be implemented. The output of it is both by noise contribution maps, evaluating each road segment and time patterns. The result is an effective urban sound planning tool that can be applied by the city, minimizing the existing gap between current urban development projects and needs and the practice of urban planning and design.

Future work will include further development of the dynamic traffic assessment and its influence on noise emission, focusing on acoustic indicators, isolating main features to test differences in transport strategies. A more advanced propagation model will be incorporated to study the influence that urban development has on the acoustic quality. In this sense, there is an opportunity to shield the noise coming from the northern infrastructures through landscape and urban design. For example, including a berm along the railroad with capacity to allocate activities underneath it, bringing a more appropriateness acoustic environment due to the activities developed, while diminishing noise exposure. In addition, there are possibilities to allocate roadside urban screens to protect pedestrians/cyclists. As a second step, and, in order to develop indicators to describe the acoustic environment and the influence on the well-being of people, listening tests will be performed.

- Rome: the historical burden of the site adds responsibility to the overall sound planning. It was shown that on the contrary of other urban areas, the main focus cannot be constrained to achieve the limits in force due to the city acoustical zoning. Promoting a participative process, including the acoustic perception of all the stakeholders, inclusive tourists', but at the same time ensuring that future proposed actions respect the heritage and promotes cultural and economic development, was part of the implemented process. The integrated approach included a first analysis of users' soundscape perception with sound pressure level measurements. This campaign was followed by the characterisation of the different sources affecting the site: road traffic and people density. Although the results are still being analysed, preliminary results indicate that, in this case, the soundscape quality does not support the visual attractiveness, nor supports the historical heritage. The traditional approach based on noise maps and acoustic measurements was integrated with a perceptual analysis providing more complete insight to the characterised situation. Future work includes objective and subjective analysis of data obtained in the survey-measurement campaign in order to get an overview of people's perception in relation to the registered acoustic parameters. Sound propagation maps will also be calculated. It is expected that based on the results, it will be possible to elaborate further concrete proposals. The ESR's working group of Rome interacted from an early beginning, with various stakeholders to advise on suitable interventions to take the most of the sound environment while respecting the identity, historical and archaeological heritage of the area. The municipality of Rome is very interested in increase the acoustic quality of the archaeological area, but it is also conscious of the complexity of the interventions due to the different authorities involved in the decision process of such areas.

The following table (Table 7) is presented as a summary of the methods, tools, findings and proposals from the four test sites.

\subsection{Implementation of the holistic approach: SWOT analysis}

The holistic approach has been carried out from the beginning of the test sites work. In this sense, the framing of the problem as well as the methodology, have been approached from a broader perspective, embracing the concept of urban planning. This demanded a constant rethinking of the current practice in sound environment as a problem-solving approach. It requires thinking far beyond noise legislation aspects, rising up the idea of an anticipatory process to avoid unnecessary costs and future problems.

In order to analyse how the holistic approach to urban sound planning is being implemented overall in SONORUS case studies, a SWOT (strengths, weaknesses, opportunities and threats) matrix was structured to consider the four test sites together (Table 8).

From the matrix emerged that SWOT factors are quite common to all test sites, and they are summarized in a single main aspect for each test site, considering the general SWOT criteria: (S) project characteristics that give advantage over others, (W) characteristics that place the project at a disadvantage relative to others, $(0)$ elements that the 


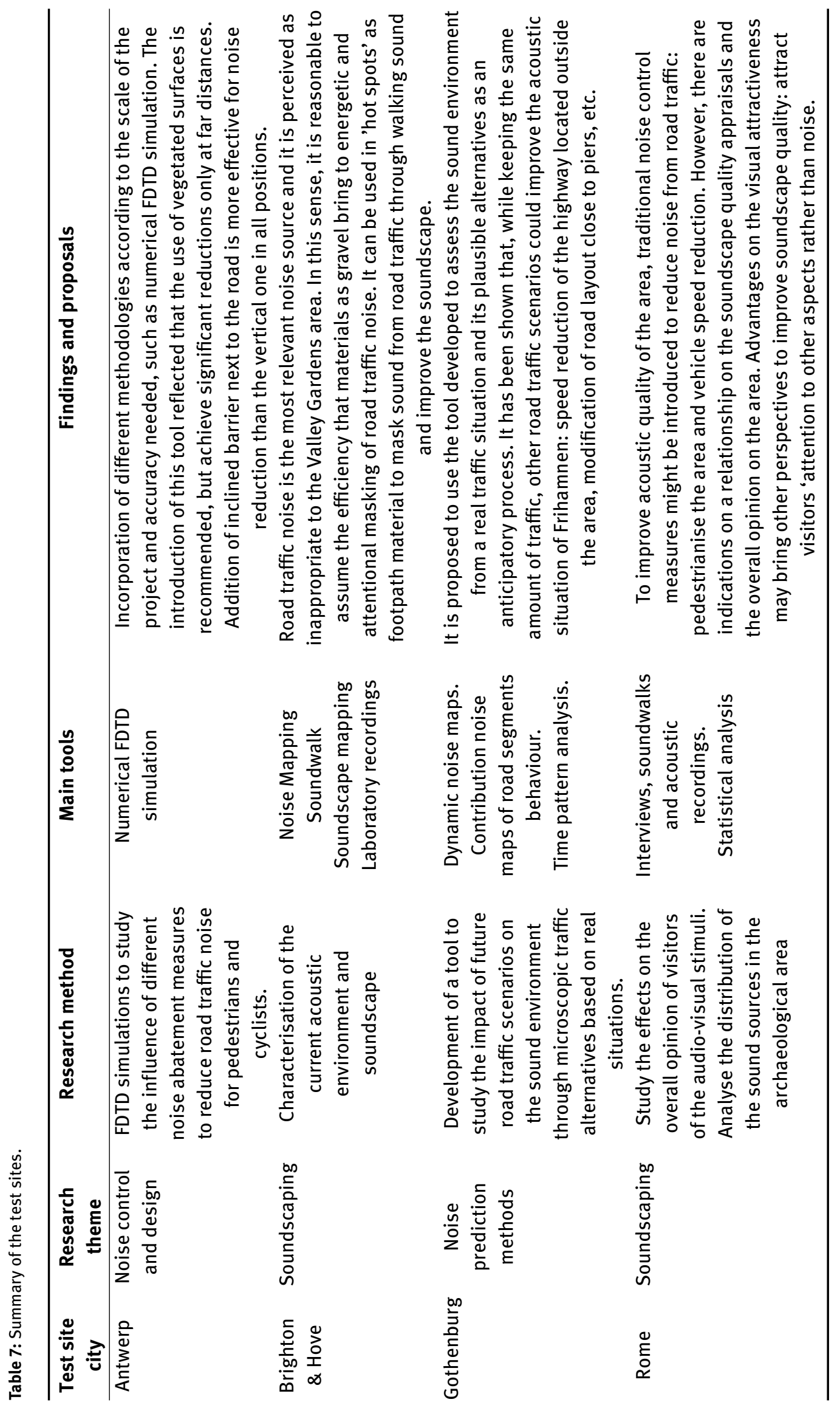




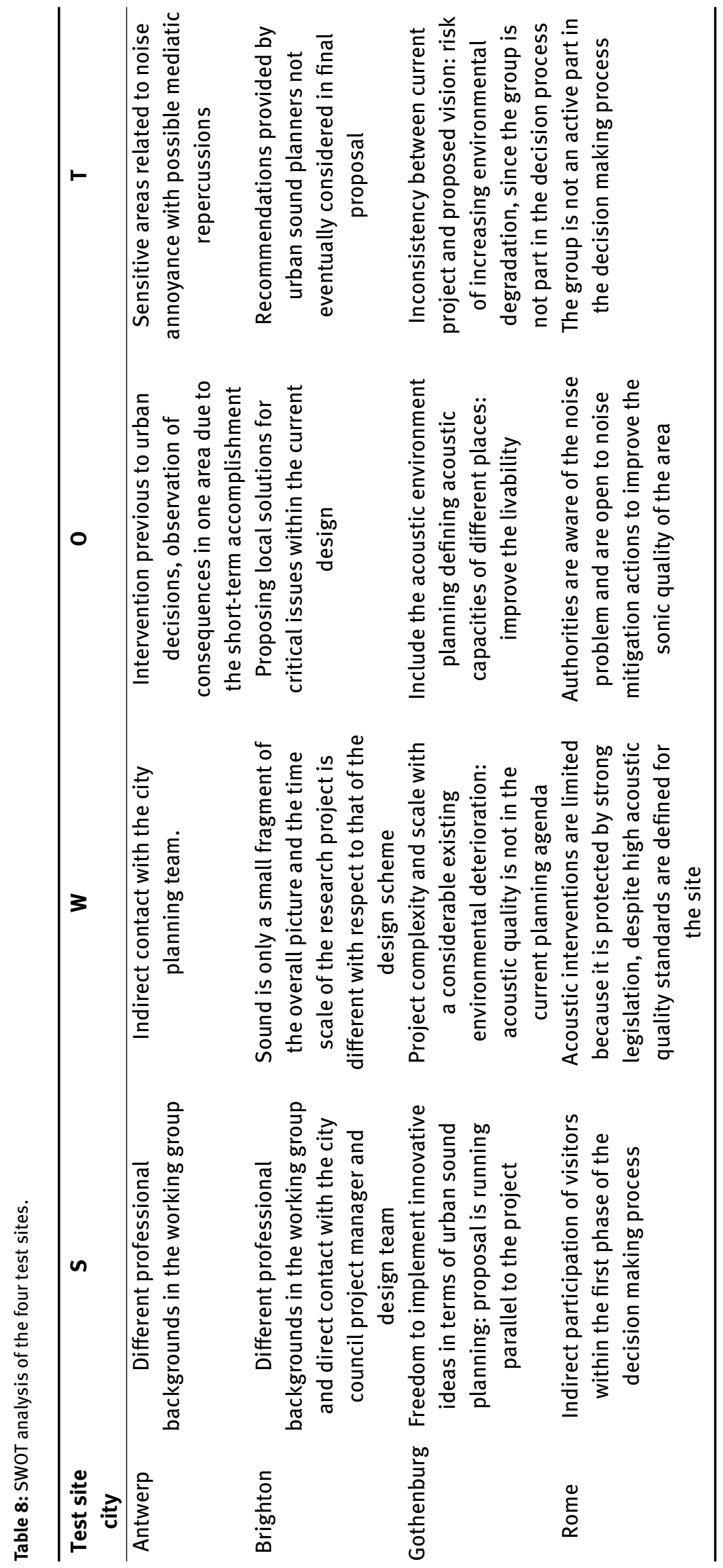


project could exploit to its advantage, and (T) elements that could cause trouble to its development and success.

Interestingly, the possibility of not seeing realized the interventions proposed by the working groups, seems to be a common concern. This raises a question about the awareness that actors and stakeholders of the planning process might have about the sound environment management and urges to rethink the role of the urban sound planner.

Another major aspect reflected as weakness in the SWOT analysis is the interaction with stakeholders and its impact in the research methodology and tools. Contact with the main stakeholders varies between the test sites. This fact may enhance but also constrain the outcomes of the study by e.g. lacking information and difficulties accessing certain stakeholders.

As an EU project, SONORUS has a fixed existence, ending in October 2016. This time window will, in most cases, not be enough to validate certain steps of the urban planning process, meaning by that its effective implementation and verification of the expected results. As discussed before, positive outcomes are already demonstrated by this approach, resulting in improved solutions and innovative tools. One of the strengths of this approach is that holistic urban sound planning shares the scope of urban planning process, which is to make spaces more liveable while efficient, avoiding the idea of an isolated action to tackle "noise issues".

\section{Conclusions}

This paper proposed and demonstrated a procedure to extend the traditional urban planning process from isolated systems. Conventionally, disconnect needs as densification, visual aesthetics', transport demands or economic reasons, are leading the projects, neglecting the idea of a holistic approach. Under this manifold, city planners demand solutions that are innovative enough to improve the livability of spaces. With this paper, we try to grasp and implement ideas under a holistic view, where actions carried out by all urban development actors generate a cascade effect that can diminish the acoustic quality of cities. However, the approach goes far beyond, raising the importance of sound as part of quality in the living environment, rejecting the narrow view of legislation and noise abatement as the only chances to include urban sound planning in the urban development agenda.

The results presented here showed that there is a wide range of possible approaches to a holistic planning that embraces sound in the urban development agenda with successful results. As stated in Antwerp, with the intention to restore a damaged sound environment, protecting pedestrians and cyclists, it was showed that using calculations methods, such as full wave FDTD numerical method to include adapted noise abatement solutions in the propagation path, may have a strong influence in the improvement of the sound environment. As for Brighton, it targets also a damaged sound environment. The outcomes show that the combined tool of road traffic noise maps, soundwalks and "sound sources' dominance map" may enhance the possibilities to intervene in the sound environment of an area from a broader perspective. The city of Gothenburg had a different approach with a large new urban development of great importance due to its strategic location. The tools used in the holistic approach analysed the sound environment from the traffic planning perspective. The dynamic noise maps tool is capable to analyse traffic time patterns and noise events, rethinking the traffic layout, studying different possibilities to improve the future acoustic environment, and its demanded qualities. Last, but not the least, the city of Rome confronts a very particular test site, where research on the history of the area, had led to different problem approaches. In order to understand its particularities, measurements and surveys has been carried out and a series of recommendations in order to improve the sound environment of the area have been delivered to the city.

Acknowledgement: This research received funding through the People Programme (Marie Curie Actions) of the European Union's $7^{\text {th }}$ Framework Programme FP7/2007-2013 under REA grant agreement $n^{\circ} 290110$, SONORUS "Urban Sound Planner".

The authors would like to thank the test site SONORUS supervisors Wolfgang Kropp, Joachim Scheuren, Jian Kang, Jens Forssén, Dick Botteldooren and Luigi Maffei for their great support and review, as well as the rest of the SONORUS supervisors: Beate Altreuther, Krister Larsson, Kurt Heutschi, Maarten Hornikx, Nicole van Hout, Rosalba Silvaggio, Salvatore Curcuruto and Timothy van Renterghem. We have also received valuable input from the rest of the ERS's students: Efstathios Margaritis, Karlo Filipan, Raúl Pagán Muñoz, Fotis Georgiou, Mercury Kounturas, Ignacio García Merino, Georgios Zachos, Freddy Rietdijk and Like Jiang. Last, we want to thank the local representatives Rebecca Beeckman, Matthew Easteal, Simon Banister, Martin Knape, Maria Holmes, Henrik Nystedt and Guido Carati for their support in this process.

This research has made use of software Vissim provided by PTV Group. 


\section{References}

[1] European Environment Agency (EEA), Noise in Europe 2014 (EAA Report No 10/2014), Publications Office of the EU, Luxembourg, 2014.

[2] World Health Organization (WHO) Regional Office for Europe, Burden of disease from environmental noise. Quantification of healthy life years lost in Europe, WHO Regional Office for Europe, Copenhagen, 2011.

[3] European Parliament and Council, Directive 2002/49/EC relating to the assessment and management of environmental noise, Publications Office of the EU, Brussels, Belgium, 2002.

[4] EEA, Urban Sprawl in Europe - The ignored challenge (EAA Report No 10/2006), Publications Office of the EU Luxembourg, 2006.

[5] WHO \& United Nations Human Settlements Programme. Hidden cities: Unmasking and overcoming health inequities in urban settings. WHO, Centre for Health Development. Kobe, Japan, 2010.

[6] D. Dodman, G. McGranahan, D. B. Dalal-Clayton, International Institute for Environment and Development, Integrating the environment in urban planning and management: Key principles and approaches for cities in the $21^{\text {st }}$ century, UNEP, Paris, 2013.

[7] S. Alves, B. Altreuther, J. Scheuren, Holistic concept for urban sound planning applied to real sites, Proceedings of Forum Acusticum Conference (2014, Krakow, Poland).

[8] A. L. Brown, Soundscapes and environmental noise management, Noise control Eng. J. 2010, 58(5), 493-500.

[9] S. Alves, B. Altreuther, J. Scheuren, Research outcomes for urban sound planning from EU projects, Proceedings of EuroNoise Conference (2015, Maastricht, The Netherlands) 1553-1558.

[10] Hosanna consortium, Novel solutions for quieter and greener cities. Hosanna workshop brochure, Hosanna Publication, Sweden, 2013. Retrieved from: http://www.greener-cities.eu/

[11] C. Mietlicki, F. Mietlicki, C. Ribeiro, P. Gaudibert, B. Vincent, The HARMONICA project, new tools to assess environmental noise and better inform the public, Proceedings of Forum Acusticum Conference (2014, Krakow, Poland).

[12] A. Gidlöf-Gunnarsson, E. Öhrström, J. Forssén, The effect of creating a quiet side on annoyance and sleep disturbances due to road traffic noise, Proceedings of Internoise Conference (2012, New York, USA).

[13] R. Bellomini, S. Luzzi, M. Carfagni, F. Borchi, L. Goveni, et al., Life+2010 Quadmap Project (Quiet Areas Definition and Management in Action Plans): The methodology tested and optimized in pilot cases in Florence, Rotterdam and Bilbao, Proceedings of Forum Acusticum Conference (2014, Krakow, Poland).

[14] T. Kihlman, W. Kropp, W. Lang, Quieter Cities of the Future Lessening the severe health effects of traffic noise in cities by emission reductions (2014, Chalmers University of Technology, Sweden). Retrieved from: http://www.ta.chalmers.se/ downloads/open/intro/SourceBook.pdf

[15] J. Scheuren, W. Kropp, J. Forssén, SONORUS - Training Urban Sound Planners by education and research, Proceedings of Forum Acusticum Conference (2014, Krakow, Poland).

[16] Algemene Directie Statistiek - Statistics Belgium - Bevolking op basis van het rijksregister van de natuurlijke personen. (2015, March 12). Retrieved from: http://statbel.fgov.be/nl/binaries/ pop2010-2013mov_nl tcm325-234223.xls

[17] K. Filipan, M. Boes, D. Oldoni, B. De Coensel, D. Botteldooren, Soundscape quality indicators for city parks, the Antwerp case study, Proceedings of Forum Acusticum Conference (2014, Krakow, Poland).

[18] D. Botteldooren, K. Filipan, M. Boes, B. De Coensel, How the meaning a person gives to tranquility could affect the appraisal of the urban park soundscape, Proceedings of Internoise Conference (2014, Melbourne Australia).

[19] L. Leden, P. E. Wikstrom, P. Garder, P. Rosander, Safety and accessibility effects of code modifications and traffic calming of an arterial road, Accident Analysis Prevent 2006, 38 (3), 455-461.

[20] D. Botteldooren, Finite-difference time-domain simulation of low-frequency room acoustic problems, J Acoust Soc Am. 1995, 98(6), 3302.

[21] G. Echevarria Sanchez, T. Van Renterghem, D. Botteldooren, The influence of urban canyon design on noise reduction for people living next to roads, Proceedings of EuroNoise Conference (2015, Maastricht, The Netherlands) 1571-1576.

[22] S. Kephalopoulos, M. Paviotti, F. Anfosso-Lédée, JRC Reference report on Common Noise Assessment Methods in EU (CNOSSOS-EU), Luxembourg: Publications Office of the EU, 2012.

[23] Brighton \& Hove City Council: A vision for Valley Gardens. Retrieved from http://www.brighton-hove.gov.uk

[24] DEFRA: Noise Maps and Charts - Brighton \& Hove. Noise Mapping England. Retrieved from http://services.defra.gov.uk/ wps/portal/noise/

[25] WHO, B. Berglund, T. Lindvall, et al, eds. Guidelines for Community Noise, Geneva, WHO, 1999.

[26] WHO, Night Noise Guidelines for Europe, Copenhagen, Denmark, WHO, Regional Office for Europe, 2009.

[27] F. Aletta, E. Margaritis, K. Filipan, V. Puyana Romero, A. Östen, J. Kang, Characterization of the soundscape in Valley Gardens, Brighton, by a soundwalk prior to an urban design intervention, Proceedings of EuroNoise Conference (2015, Maastricht, The Netherlands) 1547-1552.

[28] Gothenburg city. River city [Goteborgs Stad. Alvstaden] Frihamnen area, Retreived from http://alvstaden.goteborg.se/ omradet/frihamnen/

[29] Gothenburg city, Environmental office, Noise mapping [Goteborgs Stad. Miljö, Bullerkartläggning], Retrieved from http:// goteborg.se/wps/portal/invanare/miljo

[30] Gothenburg city, Environmental Administration. City of Gothenburg Noise action plan 2014-2018. [Göteborg Stads Åtgärdsprogram mot buller 2014-2018], Gothenburg, 2015.

[31] L. Estévez-Mauriz, J. Forssén, W. Kropp, G. Zachos, Traffic dynamics, road design and noise emission: a study case, Proceedings of EuroNoise Conference (2015, Maastricht, The Netherlands) 1541-1546.

[32] Survey 2013. Museums, Monuments and Archaeological areas. Italian Ministry of cultural heritage and tourism [Ministero dei beni e delle attività culturale e del turismo].

[33] Framework Italian law on noise pollution n. 447 of $26^{\text {th }}$ October 1995 [Legge quadro sull'inquinamento acustico], Gazzetta Ufficiale della Repubblica Italiana n. 254.

[34] Acoustic Classification Plan of Rome approved in the Minutes of the City Council through the resolution no. 60 ( $23^{\text {rd }}$ May 2002).

[35] D.P.C.M. 14th November 1997, Determination of the limit values of the sound sources [Determinazione dei valori limite delle 
sorgenti sonore], Gazzetta Ufficiale della Repubblica Italiana $\mathrm{n}$. 280.

[36] F. Aletta, J. Kang, Soundscape approach integrating noise mapping techniques: a case study in Brighton, UK, Noise Mapping 2015, 2, 1-12. 